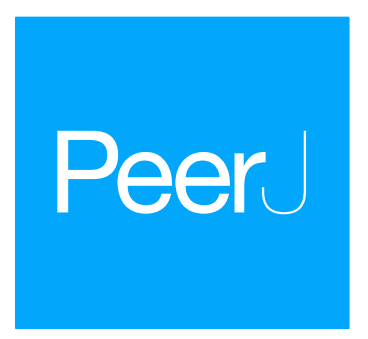

Submitted 28 January 2019

Accepted 18 March 2019

Published 29 April 2019

Corresponding author

Sophie

von der Heyden, svdh@sun.ac.za

Academic editor

Jasmine Janes

Additional Information and Declarations can be found on page 19

DOI 10.7717/peerj.6806

Copyright

2019 Phair et al.

Distributed under

Creative Commons CC-BY 4.0

OPEN ACCESS

\section{Shared genomic outliers across two divergent population clusters of a highly threatened seagrass}

\author{
Nikki Leanne Phair ${ }^{1}$, Robert John Toonen ${ }^{2}$, Ingrid Knapp ${ }^{2}$ and Sophie \\ von der Heyden ${ }^{1}$ \\ ${ }^{1}$ Department of Botany and Zoology, University of Stellenbosch, Stellenbosch, South Africa \\ ${ }^{2}$ Hawaii Institute of Marine Biology, University of Hawaii at Manoa, Kaneohe, Hawai'i, \\ United States of America
}

\section{ABSTRACT}

The seagrass, Zostera capensis, occurs across a broad stretch of coastline and wide environmental gradients in estuaries and sheltered bays in southern and eastern Africa. Throughout its distribution, habitats are highly threatened and poorly protected, increasing the urgency of assessing the genomic variability of this keystone species. A pooled genomic approach was employed to obtain SNP data and examine neutral genomic variation and to identify potential outlier loci to assess differentiation across 12 populations across the $\sim 9,600 \mathrm{~km}$ distribution of $Z$. capensis. Results indicate high clonality and low genomic diversity within meadows, which combined with poor protection throughout its range, increases the vulnerability of this seagrass to further declines or local extinction. Shared variation at outlier loci potentially indicates local adaptation to temperature and precipitation gradients, with Isolation-by-Environment significantly contributing towards shaping spatial variation in $Z$. capensis. Our results indicate the presence of two population clusters, broadly corresponding to populations on the west and east coasts, with the two lineages shaped only by frequency differences of outlier loci. Notably, ensemble modelling of suitable seagrass habitat provides evidence that the clusters are linked to historical climate refugia around the Last Glacial Maximum. Our work suggests a complex evolutionary history of $Z$. capensis in southern and eastern Africa that will require more effective protection in order to safeguard this important ecosystem engineer into the future.

Subjects Biodiversity, Ecology, Genomics, Marine Biology

Keywords Isolation by Distance, Isolation by Environment, genomic variation, Outlier loci, SDM, Seagrass, Zostera capensis

\section{INTRODUCTION}

Despite potentially high levels of gene flow, signals of local adaptation to environmental factors such as salinity and temperature gradients, have been described for a diverse set of marine species (Guo et al., 2015; Guo, Li \& Merila, 2016; Dalongeville et al., 2018; Nielsen et al., 2018), and to osmotic niches in freshwater species (Dennenmoser et al., 2016; Attard et al., 2018; Lucek et al., 2018). These and other studies suggest that contemporary spatial patterns of outlier loci significantly contribute towards shaping genetically structured populations (Savolainen, Lascoux \& Merilä, 2013; Yeaman, 2013; Huang et al., 2014; 
Tigano \& Friesen, 2016; Barth et al., 2017; Cure et al., 2017; Marques, 2017), although their relevance to local adaptation is often unknown. While standing genomic variation is the material on which selection can act, adaptive variation is expected to increase evolutionary resilience by improving the ability to persist through and adapt to changing environmental conditions (Bible \& Sanford, 2016). However, in addition to present-day environmental conditions, historical processes should also be considered, as they often play an important role in shaping contemporary patterns of genomic diversity and differentiation (Hewitt, 2000; Gaither et al., 2015; Toms et al., 2014; Leprieur et al., 2016; Chefaoui, Duarte \& Serrão, 2017; Hernawan et al., 2017), that could impact the distribution and maintenance of contemporary patterns of neutral and potentially adaptive variation. If the latter is linked to gene regions of known function, this may signal some adaptive importance (Angeloni et al., 2012; Hoban et al., 2016) and can better our understanding of the mechanisms behind adaptation.

RADSeq (Restriction Site Associated DNA Sequencing) methods have been used to investigate outlier loci and have identified both directional (Hohenlohe et al., 2010; Lexer, Wüest \& Mangili, 2014; Gaither et al., 2015) and stabilising selection patterns consistent with adaptation in several studies (Hohenlohe et al., 2010; Gaither et al., 2015), providing unique insights into the evolutionary mechanisms of non-model species. However, our understanding of how spatial variation of outlier loci among populations might contribute towards shaping population divergence in natural systems can still be further developed. In addition, it can be challenging to disentangle the signatures of potential adaptation to different environments from the simple isolating effect of distance, especially as a high degree of collinearity exists between environmental gradients and neutral population structure (Wang \& Bradburd, 2014; Manthey \& Moyle, 2015; Prunier et al., 2017; Weber et al., 2017; Rodríguez-Zárate et al., 2018). In broad spatial and environmental contexts, both Isolation By Distance (IBD) and Isolation By Environmental (IBE) will act in differentiating populations. While patterns of IBD have been observed in organisms across a range of life histories and taxonomic groups (Kelly, MacIsaac \& Heath, 2006; Van Dijk et al., 2009; Harris \& Taylor, 2010; Moura et al., 2014; Wright et al., 2015), the contribution of IBE in marine systems is becoming more apparent (Limborg et al., 2009; Mendez et al., 2010; Whittaker \& Rynearson, 2017).

Within this context, determining the spatio-temporal patterns of genomic variability that may provide some insights into signals of adaptation of populations, is important for understanding persistence and resilience of species (Sexton, Hangartner \& Hoffmann, 2014; Bernatchez, 2016), especially those under threat from environmental pressures. Importantly, detecting potentially adaptive variation can assist in pinpointing conservation units, as local adaptation is an important part of evolutionary diversification, even on a contemporary timescale (Bible \& Sanford, 2016; Bonin et al., 2007; Carvalho et al., 2011; Funk et al., 2012; Hanson et al., 2017; Von der Heyden, 2017). Globally, seagrasses are facing persistent declines and habitat fragmentation (Orth et al., 2006; Waycott et al., 2009), both of which have been linked to loss of genetic diversity (Orth et al., 2006; Williams, 2017). Decreased population sizes and loss of genetic diversity are particularly important in the 
face of climate change and habitat alteration facing coastal systems such as the habitat of the southern and eastern African seagrass, Zostera capensis (Setchell; family Zosteraceae).

Zostera capensis has a disjunct distribution limited to estuaries on the cool-temperate biogeographic region on the west coast, the warm-temperate south coast and the subtropical east coast of South Africa, where it is the dominant seagrass, and extends up the tropical east African coast to sheltered bays in Kenya. The wide distribution range of this vulnerable species (IUCN; Short et al., 2010; Green \& Short, 2003; Fig. 1A) encompasses strong environmental gradients across multiple biogeographic regions providing an excellent opportunity to study the genomic variation of relatively isolated populations along a wide gradient of environmental conditions. Zostera capensis likely relies largely on vegetative reproduction (Greve \& Binzer, 2004; Hall, Hanisak \& Virnstein, 2006), as flowering in this species has only been recorded once under specific laboratory conditions (McMillan, 1980). Unfortunately, the dispersal potential of vegetative fragments is unlikely to provide meaningful connectivity between sites due to harsh coastal conditions, strong currents and often long distances between suitable estuarine habitats (Weatherall et al., 2016).

Previous studies have shown that the genetic diversity, clonality and connectivity of seagrasses globally is highly context dependent (Jover et al., 2003; Olsen et al., 2004; Procaccini, Olsen \& Reusch, 2007; Sinclair et al., 2014; Arriesgado et al., 2016; Kendrick et al., 2016; Hernawan et al., 2017; Putra et al., 2018), with some studies reporting high genetic diversity and population structuring at regional and local scales (Diekmann et al., 2005; Van Dijk \& Van Tussenbroek, 2010; Becheler et al., 2010; Sherman et al., 2016), emphasizing the role of near and off-shore currents (Muñiz Salazar et al., 2005; Nakajima et al., 2014). Conversely, in a few cases, low levels of genetic diversity and shared genotypes, even across exceptionally large spatial scales, have been recorded (Van Dijk \& Van Tussenbroek, 2010; Evans et al., 2014; Nakajima et al., 2014; Phan et al., 2017). So-called 'mega clones' of Thalassia testudinum can even have single ramets dispersed over $47 \mathrm{~km}$ (Bricker et al., 2018) and 'millenary clones' of Posidonia oceanica are estimated to be hundreds to thousands of years old (Arnaud-Haond et al., 2012; Ruggiero, Turk \& Procaccini, 2002). However, how patterns of natural variation and population genomic structure in seagrass are shaped by adaptive processes remains poorly explored.

Changing African seascapes, through anthropogenic and changing climate pressures (Mead et al., 2013), are severely impacting local populations of $Z$. capensis, prompting calls to monitor and map genomic variation, both for neutral and outlier loci that may indicate some adaptive variation. We utilised a pooled RADseq approach to identify patterns of variation in both neutral and outlier loci for populations throughout the total range of $Z$. capensis, with the underlying hypothesis that signals of outliers would vary among populations, given that each site experiences a unique combination of environmental conditions. We also examined the predicted historical distribution by means of hindcast species distribution modelling, as historical conditions are likely to have a strong influence on contemporary patterns of diversity in southern Africa (Toms et al., 2014). Lastly, we examine the role of geographical and ecological distance in shaping patterns of variation of $Z$. capensis in its environmentally heterogeneous habitat and hypothesise that IBE will be at least as important as IBD in driving genomic diversity. 


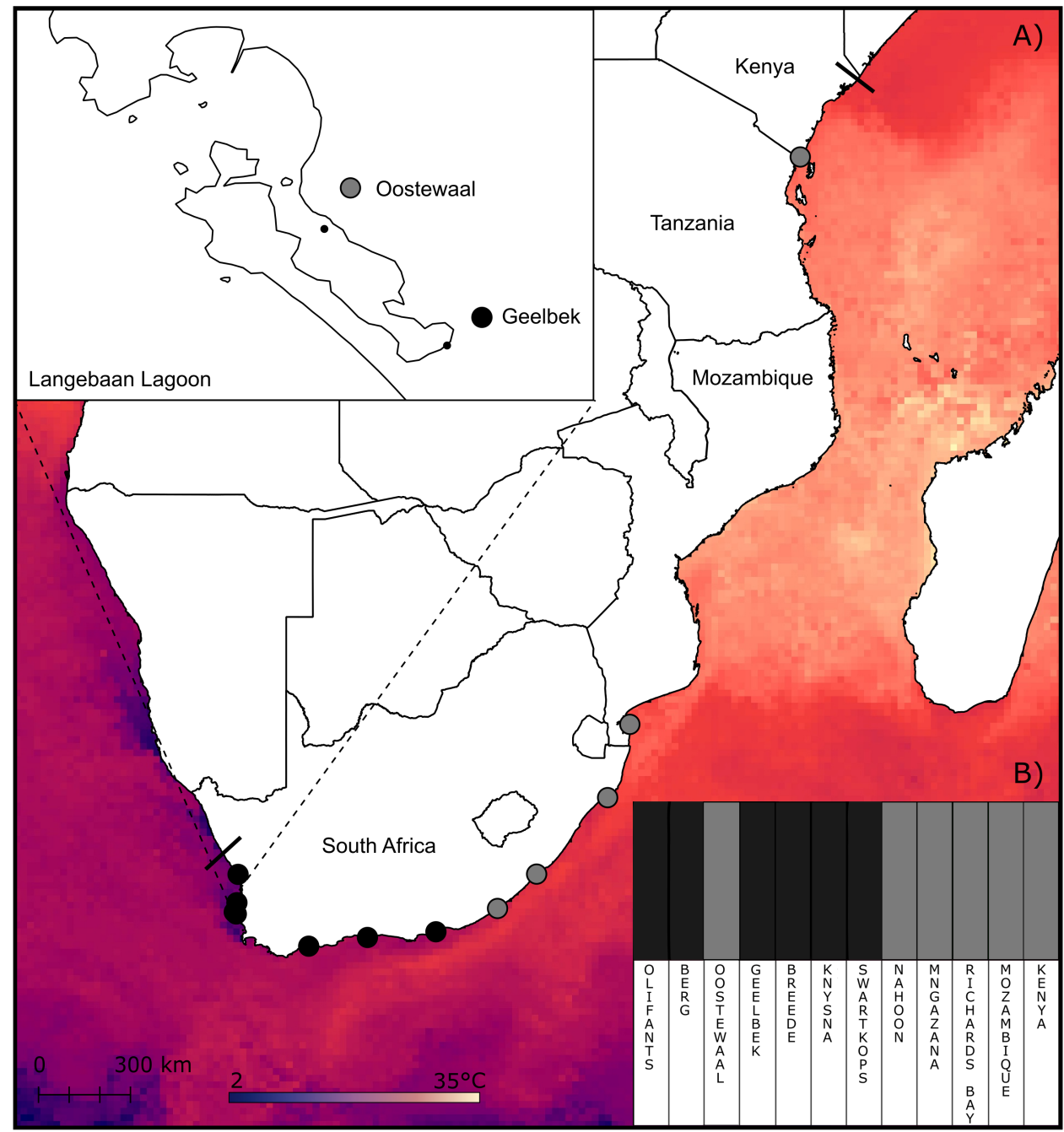

Figure 1 Sampling sites and clustering of $Z$. capensis populations. (A) Map showing the sampling sites and sea surface temperature across the range of $Z$. capensis (indicated by the solid lines). An inset of the two sites at Langebaan Lagoon is provided. (B) Clustering analysis of the twelve sites estimated in BAPS for the complete dataset, with the twelve sites grouped into two clusters.

Full-size DOI: 10.7717/peerj.6806/fig-1

\section{MATERIALS AND METHODS}

\section{Sample collection}

Leaf samples $(n=336)$ were collected from 12 sites, including nine estuaries/estuarine bays along the South African coast, one bay in Mozambique (Inhaca) and one bay in Kenya (Shimoni; Fig. 1A; Table 1). At each location, with the exception of Inhaca, and Shimoni, three leaf samples were collected $2 \mathrm{~m}$ apart from five beds at two sub-sites $(>100 \mathrm{~m})$ for a total of 30 leaf samples per location. This sampling approach was designed to minimise the sampling of clones. Samples were preserved with silica crystals before being processed. Sampling permits were granted by SanParks and CapeNature (permit number 0028-AAA008-00159); DAFF and DEA (permit number was RES2014/103). 
Table 1 Sampling locations, biogeographic zone and number of samples $(N)$ per site.

\begin{tabular}{lllll} 
Location & Abbreviation & Coordinates & & Biogeographic zone \\
\hline Olifants & $\mathrm{O}$ & $31.7021^{\circ} \mathrm{S}$ & $18.1876^{\circ} \mathrm{E}$ & Cool-temperate Namaqua \\
Berg & $\mathrm{B}$ & $32.7697^{\circ} \mathrm{S}$ & $18.1438^{\circ} \mathrm{E}$ & Cool-temperate Namaqua \\
Geelbek, Langebaan & $\mathrm{L} 1$ & $33.1941^{\circ} \mathrm{S}$ & $18.1211^{\circ} \mathrm{E}$ & Cool-temperate Namaqua \\
Oostewaal, Langebaan & $\mathrm{L} 2$ & $33.1214^{\circ} \mathrm{S}$ & $18.0447^{\circ} \mathrm{E}$ & Cool-temperate Namaqua \\
Breede & $\mathrm{BR}$ & $34.4074^{\circ} \mathrm{S}$ & $20.8453^{\circ} \mathrm{E}$ & Warm-temperate Agulhas \\
Knysna & $\mathrm{K}$ & $34.0791^{\circ} \mathrm{S}$ & $23.0562^{\circ} \mathrm{E}$ & Warm-temperate Agulhas \\
Swartkops & $\mathrm{SK}$ & $33.8650^{\circ} \mathrm{S}$ & $25.6333^{\circ} \mathrm{E}$ & Warm-temperate Agulhas \\
Nahoon & $\mathrm{N}$ & $32.9864^{\circ} \mathrm{S}$ & $27.9517^{\circ} \mathrm{E}$ & Warm-temperate Agulhas \\
Mngazana & $\mathrm{M}$ & $31.6921^{\circ} \mathrm{S}$ & $29.4228^{\circ} \mathrm{E}$ & Suptropical Natal \\
Richards Bay & $\mathrm{RB}$ & $28.8105^{\circ} \mathrm{S}$ & $32.0947^{\circ} \mathrm{E}$ & Suptropical Natal \\
Inhaca, Mozambique & $\mathrm{MOZ}$ & $26.0500^{\circ} \mathrm{S}$ & $32.9297^{\circ} \mathrm{E}$ & Tropical Delagoa \\
Shimoni, Kenya & $\mathrm{KEN}$ & $4.6741^{\circ} \mathrm{S}$ & $39.3440^{\circ} \mathrm{E}$ & Tropical \\
\hline
\end{tabular}

Despite intensive questioning of collaborators and other contacts throughout this study, no samples of $Z$. capensis were obtained from Tanzania (L Nordlund, pers. comm., 2015).

\section{Laboratory protocols}

Accurately estimating genome-wide variation and detecting signals of local adaptation in non-model organisms, such as seagrasses, requires many individuals from many sites to be sequenced, which can be prohibitively expensive despite the advances made by highthroughput sequencing methods such as RADseq (Ellegren, 2014; Andrews et al., 2016). As such, a pooled sequencing (pool-seq) approach was utilised, combining the genomic DNA of multiple individuals before sequencing (Sham et al., 2002; Kofler, Betancourt \& Schlötterer, 2012). This approach decreases cost whilst increasing the number of individuals analysed and allowing for a more population focussed analysis (Futschik \& Schlötterer, 2010; Schlötterer et al., 2014).

Genomic DNA was extracted from leaf tissue using Qiagen DNeasy plant kit (Qiagen, Valencia, USA) following standard protocols, with the exception of eluting the DNA in nuclease-free water instead of elution buffer. Genomic DNA quality was then assessed using gel electrophoresis and DNA concentrations of each sample determined by Qubit analysis at the Central Analytical Facility of Stellenbosch University (CAF). Genomic DNA was pooled by location, with all individuals having equimolar representation, to create a total of 12 samples for Illumina sequencing. The two sites at Langebaan, Oostewaal and Geelbek (Fig. 1A), were kept as separate pools to allow for comparison between the observed morphotypes; one short and stunted on the muddy tidal flats (Geelbek) which experience prolonged exposure to conditions outside the water and the other is longer with a higher biomass on the sandy permanently submerged area (Oostewaal) (D Pillay, pers. comm., 2014).

Library preparation and sequencing followed the ezRAD method (Knapp et al., 2016; Toonen et al., 2013; Nielsen et al., 2018), which obtains a reduced representation sequencing library using high frequency restriction enzymes. Pooled genomic DNA was freeze dried 
before library construction following the protocol of Knapp et al. (2016) and Mi-Seq Illumina sequencing (V3 2x300) conducted at the Genetics Core Facility (GCF) of the Hawaii Institute of Marine Biology (HIMB). These data are stored in the National Center for Biotechnology Information's (NCBI's) Sequence Read Archive (SRA; PRJNA503110) and georeferenced at GeOMe (https://geome- $\mathrm{db}$.org) at the project: Zostera capensis pooled RADseq.

\section{Data processing and alignment}

Quality of raw reads was analysed using FastQC (Andrews, 2010) and quality filtering carried out using FastQC Toolkit (Andrews, 2010), removing low quality bases ( $<20$ phred score). Additionally, TrimGalore! v 0.4.4 (available at: http://www.bioinformatics.babraham.ac. uk/projects/trim_galore/) was used to remove any remaining adapter sequences or reads shorter than $30 \mathrm{bp}$. BWA-MEM ( $\mathrm{Li}, 2013)$ was used to map filtered paired-end reads from each pooled sampling site to the genome of sister species, Zostera marina (available from NCBI, BioProject number PRJNA41721, GenBank accession number LFYR00000000 (Olsen et al., 2016), with a minimum mapping quality of 20 . Ambiguously mapped reads, PCR duplicate reads, reads with less than 20 mapping quality and less than 20 base quality were filtered out before converting SAM files to BAM files with SAMtools ( $L i$ et al., 2009). Number of mapped and unmapped reads were then calculated using the idxstats command in SAMtools. As pools with a higher number of mapped reads may have an artificially inflated number of SNPs, mapped reads were subsampled to median coverage in SAMTools using the view command with the '-s' flag. Although subsampling results in a loss of data, it is nonetheless important for correctly interpreting true differences between the sampling sites, as opposed to differences in data quality or quantity (Schlötterer et al., 2014). To confirm that subsampling removed any possible correlation between the number of mapped reads and the number of SNPs and outlier loci identified downstream, Spearman's correlation coefficients were calculated using the rcorr function of the 'Hmisc' (Harrell Jr \& Dupont, 2006) package in $\mathrm{R}$ ( $R$ Core Development Team, 2008). BAM files were sorted and indexed before being used to create pileup files for each individual sampling site with the mpileup command in SAMTools (Li et al., 2009), using a minimum quality score of 20 and maximum read depth of 10,000. Finally, a pileup file combining all sites was created using the same parameters in SAMtools and converted to a sync file using PoPoolation2 (Kofler, Pandey \& Schlötterer, 2011) for downstream use.

\section{Calling SNPs and simulating data}

The total number of SNPs and private SNPs were identified using snp-frequency-diff.pl in PoPoolation2 (Kofler, Pandey \& Schlötterer, 2011) with genomic sites required to have a minimum minor allele count of four, and coverage between 10 and 500 across all 12 sampling sites. SNPs were then filtered to retain only those present among sampling sites, and not those present due to differences between the reference sequence ( $Z$. marina) and $Z$. capensis. As many software cannot handle pooled data, requiring individuals to be specified within sampling sites, subsample_sync2GenePop.pl in PoPoolation2 was used to simulate a multi-locus dataset of a subset of SNPs identified by PoPoolation2. Because this programme 
cannot simulate different numbers of individuals across sites, the median sample size of 30 individuals was selected for every site. The resulting GenePop file was then converted to various formats in PGDspider (Lischer \& Excoffier, 2012) for downstream analyses.

\section{Outlier loci identification and functional annotation}

Due to the uncertainty surrounding RADseq, Pool-seq and outlier detection methods (Narum \& Hess, 2011; Da Fonseca et al., 2016; Mckinney et al., 2016; Lowry et al., 2017; O'Leary et al., 2018), four outlier detection methods were employed, namely BayeScan v2.1 (Foll \& Gaggiotti, 2008), Lositan (Antao et al., 2008), BayeScEnv (De Villemereuil $\&$ Gaggiotti, 2015) and PCadapt (Luu, Bazin \& Blum, 2016), which includes $F_{S T}$-based approaches, genotype-environment correlations and principle component analyses (see supplementary materials for details).

Outlier loci identified by two or more methods were considered "candidate outliers" and their functional roles evaluated by subjecting 1,000 base pairs upstream and downstream of each of the identified outlier SNPs to BLASTx searches, with the non-redundant protein sequence database and an $E$-value cut off of $10^{-5}$ (Altschul et al., 1997) using Blast2Go (Conesa et al., 2005). In addition to BLASTing against the general NCBI database, these searches were also carried out against the Zosteraceae family in general, specifically, Zostera marina (Olsen et al., 2016) and Z. muelleri (Lee et al., 2016). Gene Ontology (GO) mapping, Interproscan (Jones et al., 2014) and annotation were performed with Blast2Go default parameters. The number and proportion of candidate outliers unique to each site and shared between pairwise sites was calculated. The overlap of outliers identified between the different approaches was visualised using the 'VennDiagram' package (Chen \& Boutros, 2011) in R. The frequency of outlier loci identified by all four approaches (Lositan, BayeScan, BayeScEnv and PCAdapt) was plotted across sampling sites using the 'ggplot2' package (Wickham, 2009) in R and listed in Table S3. A one-way analysis of variance (ANOVA) and a post hoc TukeyHSD test, were performed with the 'aov' and 'TukeyHSD' functions in $\mathrm{R}$, to compare outlier frequencies across sites.

\section{Neutral variation}

All identified outlier loci were flagged as being putatively under selection for the purposes of this analysis and were therefore removed from the dataset to isolate neutral drivers of patterns of population structure. The neutral-only multi-locus dataset set was then re-simulated, using subsample_sync2GenePop.pl in PoPoolation2 with 30 individuals per site as described above, and used to calculate measures of neutral variation.

\section{Genome-wide variation and differentiation}

To characterise genetic diversity, Tajima's nucleotide diversity $(\pi)$, Watterson's theta $(\theta)$ and Tajima's D were estimated for the complete and neutral-only datasets using a sliding window approach with Variance-sliding.pl in PoPoolation v1.2.2 (Kofler et al., 2011). For these comparisons, filtering stringency was reduced to a minimum minor allele count of two and coverage between 10 and 500 per sampling site. As the estimation of allele frequencies in pooled individuals is highly reliant on sequence coverage, a high sequence coverage and large sliding windows were used in order to increase accuracy (Kofler et al., 
2011). Observed and expected heterozygosity and the inbreeding coefficient $\left(F_{I S}\right)$ was estimated from the simulated datasets with the divBasic function of the 'DiveRsity' package (Keenan et al., 2013) in R.

To investigate genome-wide levels of differentiation, the fixation index $\left(F_{S T}\right)$ for pairwise comparisons of populations was estimated using a sliding window approach with fst-sliding.pl in PoPoolation2, using a minimum minor allele count of four and a coverage between 10 and 500. Fisher's exact test was carried out with fisher-test.pl in PoPoolation2 to estimate the significance of allele frequency differences between sites. Patterns of differentiation were visualised on a principle coordinates analysis (PCoA) plot generated in R using the pco function of the 'labdsv' package (Roberts, 2007). The PCoA plot was generated both with and without Kenya in order to account for sampling bias. The simulated neutral dataset was used to investigate population clustering by means of Bayesian Analysis of Population Structure (BAPS) software (Corander \& Marttinen, 2006; Corander, Marttinen \& Mäntyniemi, 2006) testing $K=1-10$.

\section{Habitat suitability for Z. capensis in the LGM}

In order to understand the influence of historical environmental conditions on the contemporary patterns of genomic variability, the suitable habitat for Z. capensis was hindcast to the Last Glacial Maximum (LGM; 21 kya). Zostera capensis occurrence data was obtained from Adams, Veldkornet \& Tabot (2016) and environmental data downloaded from MARSPEC at 5 arcminute resolution for both the present-day (Sbrocco $\&$ Barber, 2013) and the LGM (CNRM-CM33 model; Braconnot et al., 2007; Sbrocco, 2014). Following Chefaoui, Duarte \& Serrão (2017), only Sea Surface Temperature (SST) of the coldest month (Biogeo14) and warmest month (Biogeo15) were utilised to avoid using strongly correlated variables for Species Distribution Modelling (SDM; Guisan \& Thuiller, 2005; Braunisch et al., 2013; Chefaoui, Duarte \& Serrão, 2017). Precipitation variables were excluded to decrease model uncertainty (Varela, Lima-Ribeiro \& Terribile, 2015). These variables represent relevant present-day and LGM conditions, which are recognised as important determinants of intertidal seagrass habitat suitability (Short Neckles, 1999; Short et al., 2010; Valle et al., 2014) and they are projected along the present-day (Sbrocco \& Barber, 2013) and LGM coastlines (Braconnot et al., 2007; Sbrocco, 2014), respectively. Environmental variables such as salinity and oxygen content were not included due to the high natural variability in estuarine systems over tidal and seasonal time-scales. QGIS (QGIS Development Team, 2012) was used to crop raster extents, by means of the buffer and crop tools, to focus on the coastal areas including and surrounding the present-day range of $Z$. capensis.

Ecological niche modelling was implemented through an ensemble approach with the 'biomod2' package (Thuiller et al., 2016) in R. As in Chefaoui, Duarte \& Serrão (2017), the following six presence-absence algorithms were included in the ensemble models: generalized additive model (GAM), flexible discriminant analysis (FDA), generalized boosting model (GBM), multiple adaptive regression splines (MARS), generalized linear model (GLM), and random forest (RF). Default parameters were used for all algorithms, except for the GLM which was fitted with a quadratic term, the GBM which was run 
with 1,000 trees, and the GAM which was executed with the GAM_mgcr function. As the occurrence data (Adams, Veldkornet \& Tabot, 2016) included reliable presence and absence records for estuaries along the entire South African coastline, no pseudo-absence selection was required. The data was split into a calibration (80\%) and a validation (20\%) set and three iterations were performed for each algorithm with three permutations to estimate and weight variable importance, for a total of 18 models. Models were assessed with the true skill statistic (TSS; Allouche, Tsoar \& Kadmon, 2006) and the area under the receiver operating characteristic (ROC) curve (AUC; Fielding \& Bell, 1997), considering both specificity (true negatives) and sensitivity (true positives). Only models scoring TSS $>0.55$ and AUC $>0.8$ were used to produce ensembles. Retained models were ensembled to produce a weighted mean SDM and first used to project the present-day habitat suitability, in terms of SST, along the South African coastline, and then used to hindcast the habitat suitability to the LGM. The present-day and LGM habitat suitability projections, as well as the changes in habitat suitability between the present-day and LGM were plotted in R.

\section{Disentangling contemporary signals of IBD and IBE}

A redundancy analysis (RDA) (Legendre \& Legendre, 2012) was conducted to evaluate the relative contribution of spatial and environmental variation to genomic variability and patterns of genetic differentiation. RDA can be useful as a multivariate regression technique when running regression analyses with multivariate predictors (space and environment) and multivariate responses (here, minor allele frequencies of SNPs). As spatial distances are not suitable for constrained ordination or regression as implemented in RDA, geographic distances were transformed to Principal Coordinates of Neighbourhood Matrix (PCNM) distances with the pcnm function in the 'vegan' package (Oksanen et al., 2015) in R. Environmental distances were calculated within the RDA function from the variables in Table 2 (excluding the macrophyte species measure, which were only available for South Africa). The ordistep function from the 'vegan' package was used to select the most informative variables and build the 'optimal' model. Four separate RDAs were conducted with minor allele frequency as the response. Predictor variables in the first RDA were transformed geographic distances, and in the second were environmental distances. Lastly, two partial RDAs were performed, partitioning out the effect of transformed geographic distance and environmental variation from the total variation respectively. The anova function of the package 'vegan' was performed with 999 permutations (Legendre, Oksanen $\&$ Ter Braak, 2011) to test the significance of RDAs.

\section{RESULTS}

\section{Sequencing and mapping}

$54,982,056$ paired reads were obtained, with paired reads from each sampling site ranging from $1,368,372$ to $7,429,328$ (Table 3 ). After filtering reads for quality and adapters, and subsampling to a median, 7,432,397 reads, ranging from 222,741 to 750,736 per site, were aligned to the $Z$. marina reference genome (Table 3 ). The number of filtered subsampled mapped reads had no correlation with the number of SNPs $(r=0.17 ; p>0.05)$ or outlier loci $(r=-0.05 ; p>0.05)$ identified. 


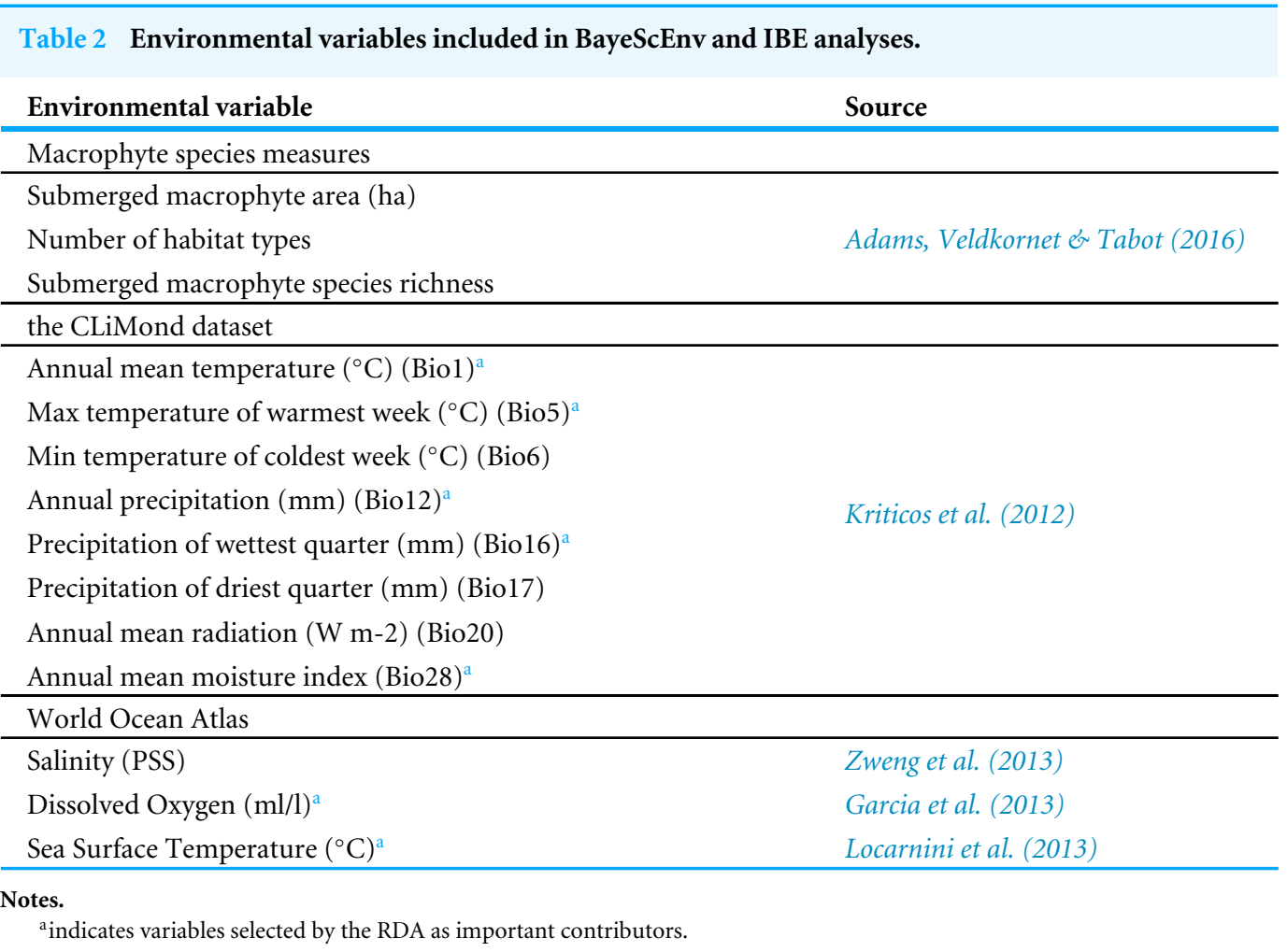

\section{Neutral and outlier loci}

The complete simulated dataset consisted of 308 loci (Fig. 3). From this dataset, 101 outlier loci were detected by Lositan, while BayeScan and BayeScEnv detected 25 and five outlier loci respectively. The five outlier loci identified by the ecological association approach in BayeScEnv were correlated with precipitation of the driest quarter and annual mean moisture levels. By analysing allele frequencies of the non-simulated dataset, PCAdapt identified 38 outlier loci. All 169 outlier loci were removed from the complete dataset in order form a neutral-only dataset with which to examine patterns of neutral variation.

\section{Genome-wide variation}

The number of SNPs identified by PoPoolation2 in the neutral and complete datasets ranged from 845 to 1,683 and 913 to 1,784 per sampling site respectively. The number of private SNPs per site was generally low and five populations did not have any private SNPs (Tables 3 and 4). The genome-wide average nucleotide diversity (Tajima's $\pi$ ) of the neutral and complete datasets ranged from 0.023 to 0.041 and 0.023 to 0.035 , respectively. Allelic richness did not vary much between sites, ranging from 1.23 to $1.36 . \theta_{\mathrm{W}}$ of the neutral and complete datasets were the same, ranging from 0.029 to 0.043 (Tables 3 and 4). The west and south coast sites, with the exception of Oostewaal (L2), exhibited marginally higher nucleotide diversity and $\theta_{\mathrm{W}}$ than the east coast sites. Tests for deviations from neutrality produced genome-wide average Tajima's $\mathrm{D}$ that were negative for all sampling sites and ranged from -0.723 to -0.275 and -0.706 to -0.273 , for the complete and neutral datasets respectively. Genetic diversity metrics calculated from the simulated datasets included expected heterozygosity ( 0.04 to 0.06 ) within each sampling site (Tables 3 and 4 ), 
Table 3 Summary statistics of RAD data and estimates of genetic diversity metrics per sampling site (refer to Table 1 for full names of abbreviations) for neutral dataset.

\begin{tabular}{|c|c|c|c|c|c|c|c|c|c|c|c|}
\hline $\begin{array}{l}\text { Sampling } \\
\text { site }\end{array}$ & Raw reads & Mapped reads & $\begin{array}{l}\text { Subsampled } \\
\text { mapped reads }\end{array}$ & SNPs & $\begin{array}{l}\text { Private } \\
\text { SNPs }\end{array}$ & $\pi$ & $\theta$ & D & $\mathrm{He}$ & Ho & $\mathrm{F}_{\mathrm{IS}}$ \\
\hline $\mathrm{O}$ & $5,862,886$ & $1,457,363$ & 743,255 & 1,278 & 2 & 0.034 & 0.041 & -0.714 & 0.04 & 0 & 1 \\
\hline B & $4,314,436$ & $1,114,902$ & 746,984 & 1,683 & 3 & 0.035 & 0.042 & -0.722 & 0.04 & 0 & 1 \\
\hline $\mathrm{L} 1$ & $4,997,550$ & $1,153,894$ & 750,031 & 1,473 & 2 & 0.034 & 0.041 & -0.698 & 0.04 & 0 & 1 \\
\hline L2 & $1,368,372$ & 222,741 & 222,741 & 1,027 & 0 & 0.025 & 0.031 & -0.616 & 0.06 & 0 & 1 \\
\hline BR & $3,105,804$ & 508,608 & 508,608 & 1,624 & 1 & 0.034 & 0.041 & -0.705 & 0.05 & 0 & 1 \\
\hline $\mathrm{K}$ & $5,943,674$ & $1,251,227$ & 750,736 & 1,342 & 1 & 0.035 & 0.041 & -0.673 & 0.04 & 0 & 1 \\
\hline $\mathrm{N}$ & $4,296,798$ & 568,703 & 568,703 & 845 & 0 & 0.028 & 0.034 & -0.654 & 0.05 & 0 & 1 \\
\hline M & $3,991,420$ & 475,470 & 475,470 & 914 & 1 & 0.025 & 0.032 & -0.637 & 0.05 & 0 & 1 \\
\hline $\mathrm{RB}$ & $7,429,328$ & 781,740 & 750,470 & 1,105 & 0 & 0.022 & 0.028 & -0.646 & 0.04 & 0 & 1 \\
\hline $\mathrm{MOZ}$ & $4,136,268$ & 719,319 & 719,319 & 598 & 0 & 0.026 & 0.028 & -0.276 & 0.05 & 0 & 1 \\
\hline KEN & $3,653,420$ & 447,966 & 447,966 & 1,480 & 6 & 0.029 & 0.043 & -0.324 & 0.04 & 0 & 1 \\
\hline Total & $54,982,056$ & $10,062,138$ & $7,432,397$ & - & 16 & - & - & - & - & - & - \\
\hline Range & $1,368,372-7,429,328$ & $222,741-1,457,363$ & $222,741-750,736$ & $845-1,683$ & $0-6$ & $0.023-0.035$ & $0.029-0.043$ & $(-0.723)-(-0.275)$ & $0.04-0.06$ & 0 & 1 \\
\hline
\end{tabular}
Notes.

$\pi$, Tajima's $\pi ; \theta$, Watterson's $\theta$; D, Tajima’s D; He, Average expected heterozygosity; Ho, Average observed heterozygosity. 


\begin{tabular}{|c|c|c|c|c|c|c|c|c|}
\hline $\begin{array}{l}\text { Sampling } \\
\text { site }\end{array}$ & $\begin{array}{l}\text { Number } \\
\text { of SNPs }\end{array}$ & $\begin{array}{l}\text { Number } \\
\text { private SNPs }\end{array}$ & $\pi$ & $\theta$ & D & $\mathrm{He}$ & Ho & $F_{\text {IS }}$ \\
\hline $\mathrm{O}$ & 1,362 & 2 & 0.034 & 0.041 & -0.716 & 0.04 & 0 & 1 \\
\hline B & 1,784 & 3 & 0.035 & 0.043 & -0.723 & 0.04 & 0 & 1 \\
\hline L1 & 1,577 & 2 & 0.034 & 0.041 & -0.700 & 0.04 & 0 & 1 \\
\hline $\mathrm{L} 2$ & 1,091 & 0 & 0.025 & 0.031 & -0.616 & 0.06 & 0 & 1 \\
\hline $\mathrm{BR}$ & 1,726 & 1 & 0.034 & 0.041 & -0.706 & 0.05 & 0 & 1 \\
\hline $\mathrm{K}$ & 1,436 & 1 & 0.035 & 0.042 & -0.674 & 0.04 & 0 & 1 \\
\hline SK & 1,483 & 0 & 0.035 & 0.042 & -0.676 & 0.04 & 0 & 1 \\
\hline $\mathrm{N}$ & 913 & 0 & 0.028 & 0.034 & -0.651 & 0.05 & 0 & 1 \\
\hline M & 997 & 1 & 0.026 & 0.033 & -0.636 & 0.05 & 0 & 1 \\
\hline $\mathrm{RB}$ & 1,192 & 0 & 0.023 & 0.028 & -0.646 & 0.04 & 0 & 1 \\
\hline $\mathrm{moz}$ & 668 & 0 & 0.027 & 0.029 & -0.273 & 0.05 & 0 & 1 \\
\hline ken & 1,580 & 6 & 0.029 & 0.043 & -0.323 & 0.04 & 0 & 1 \\
\hline Total & - & 16 & - & - & - & - & - & - \\
\hline range & $913-1,784$ & $0-6$ & $0.023-0.041$ & $0.029-0.043$ & $(-0.706)-(-0.273)$ & $0.04-0.06$ & 0 & 1 \\
\hline
\end{tabular}

Notes.

$\pi$, Tajima's $\pi ; \theta$, Watterson's $\theta$; D, Tajima's D; He, Average expected heterozygosity; Ho, Average observed heterozygosity.

and the inbreeding coefficient, $F_{\text {IS }}$, which was uniform across sampling sites and equal to 1 , for both the complete simulated dataset and the neutral simulated dataset. Although an $F_{\text {IS }}$ of 1 is partly due to the nature of the simulated data, generating multiple individuals from a highly clonal pool, it nonetheless indicates extremely high levels of inbreeding.

\section{Genome-wide differentiation and clustering}

$F_{S T}$ values were estimated from the complete non-simulated dataset for pairwise comparisons of sites (Tables S1, S2), with Fisher's exact tests showing no significant differentiation between pairs of sites for either dataset. Similarly, clustering analysis conducted in BAPS on neutral loci revealed no structure across sites, with all sites falling into one cluster $(K=1 ; p<0.05$; Fig. S1). Although there is no significant population structuring, the PCoA (Fig. 2) of pairwise $F_{S T}$ values for neutral loci suggests that the west and south coast sites, (except for Oostewaal-L2), are more closely related than the east coast sites. The same pattern was observed for the PCoA generated without Kenya (Fig. 2).

However, when the clustering analysis in BAPS included outlier loci, two clusters were detected ( $p<0.05$; labelled cluster one and two), with cluster one comprising samples from the west and south coasts, and cluster two including populations from the east coast of South Africa in addition to Mozambique and Kenya (Fig. 1B). Notably, one west coast site in Langebaan, Oostewaal (L2), groups with cluster two rather than cluster one (Fig. 1B).

PCoAs of pairwise $F_{S T}$ comparisons from the complete dataset and all outlier loci resulted in a similar, but slighter denser pattern than observed for the neutral dataset (Fig. 2). Sites from cluster one formed a tight group, relatively separate from the remaining sites. Sites from cluster two did not group as closely as those from cluster one, with Mozambique most differentiated. Moreover, Mozambique, followed by Kenya, exhibited much higher outlier allele frequencies than other sites (Table S3). 

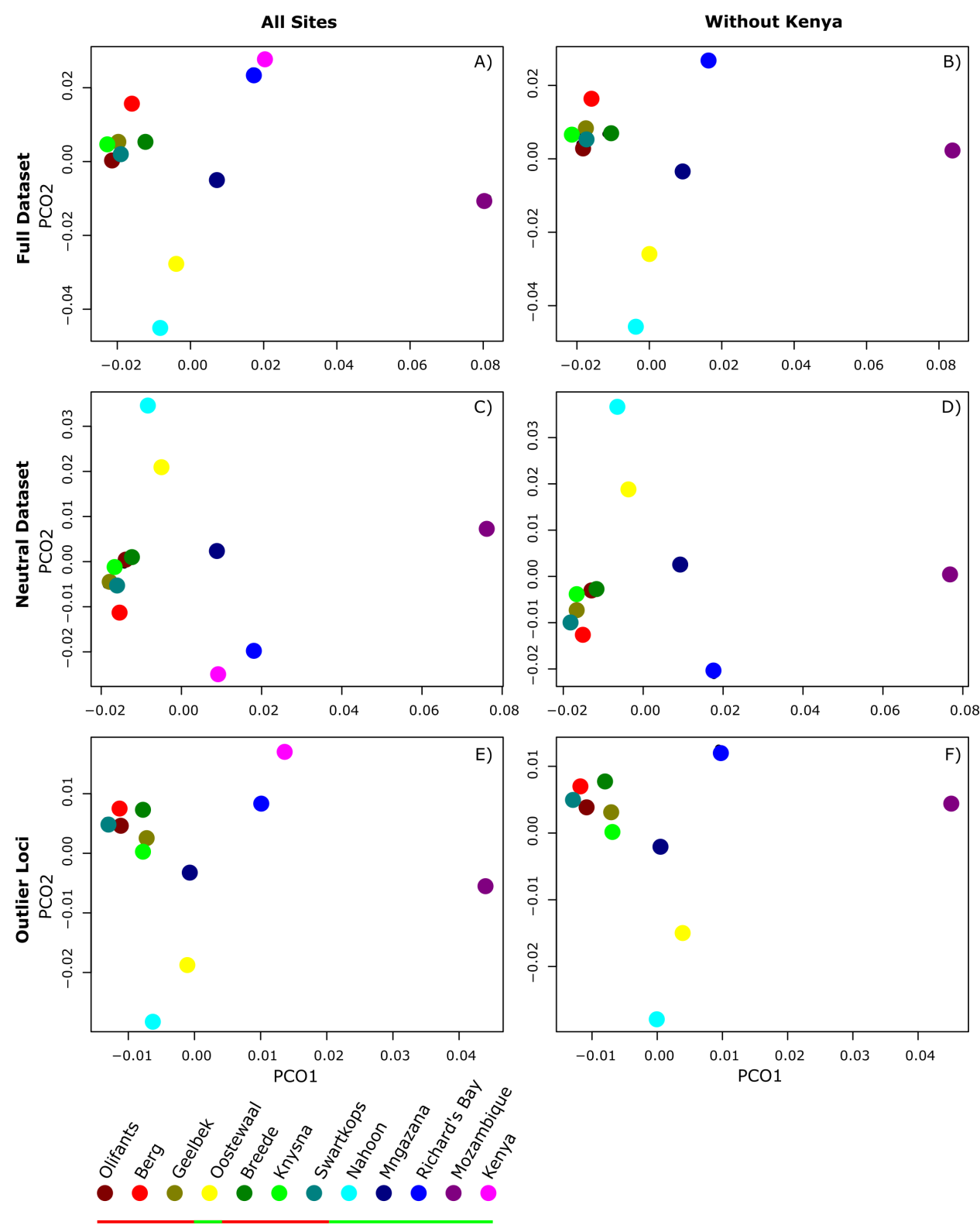

Figure 2 Principle Coordinate Analysis (PCoA) plots of average pairwise. Principle Coordinate Analysis (PCoA) plots of average pairwise $\mathrm{F}_{\mathrm{ST}}$ comparisons among all 12 sampling sites $(\mathrm{A}, \mathrm{C}, \mathrm{E})$ and all sites excluding Kenya (B, D, F) for all loci in the complete dataset (A, B), the subset of loci contained in the simulated neutral dataset (C, D), and outlier loci (E, F). Sites grouping with cluster one and two are indicated by the red and green bar in the legend, respectively.

Full-size DOI: 10.7717/peerj.6806/fig-2

While some outlier loci were identified by more than one method, there was little overlap between outlier loci identified using the four different approaches (Fig. 3), with only three outliers shared between all four methods. However, irrespective of how many outlier loci are included, the frequency at which outlier loci occurred at each site reflects the two clusters identified using BAPS (Fig. 1B). ANOVA and post hoc TukeyHSD tests revealed 

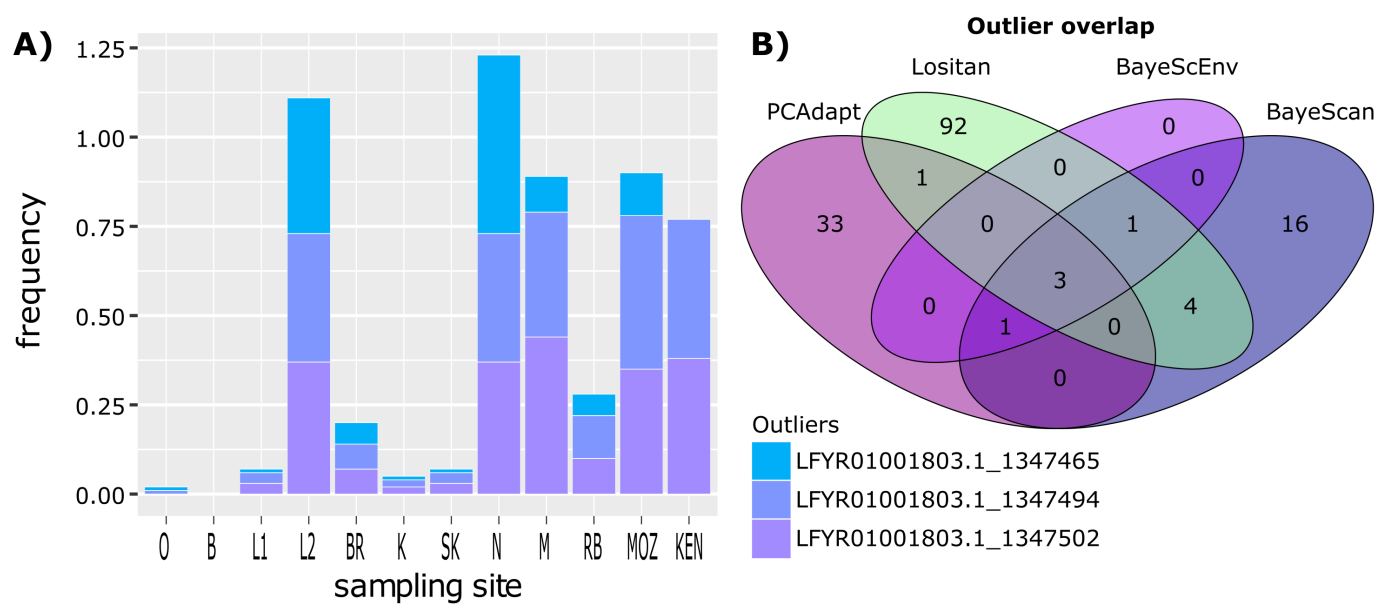

Figure 3 Outlier frequency and identification overlap. (A) The frequency of the three outlier loci identified by all four approaches (Lositan, BayeScan, BayeScEnv and PCAdapt) across sampling site. (B) Venn diagram illustrating the overlap between outlier loci identified using the four different approaches.

Full-size DOI: 10.7717/peerj.6806/fig-3

that outlier frequencies were not significantly different across sampling sites $(p>0.05)$ but that they were significantly different across the two clusters, with higher frequencies observed in cluster 2 than cluster $1\left(F_{1,24}=66.61, p<0.001\right.$; Fig. 3$)$. No private outliers were identified as all outlier loci occurred at two or more sites and all candidate outliers (identified by more than one method) occurred at most of the sites (Table S3).

\section{Functional annotation of candidate outlier loci}

Two-thousand base pairs surrounding each of 10 candidate outlier loci were subjected to the Blast2Go pipeline. Although all of the 10 candidate outliers yielded significant hits when BLAST searches were conducted against the general NCBI database, Zosteraceae, $Z$. marina and Z. muelleri, the majority of these hits did not fall within gene regions of known function. GO terms (GO:0016020-IEA 'membrane' and GO:0016021-IEA 'integral component of membrane') were assigned to five of the 10 candidate outlier loci with BLAST matches to hypothetical and predicted proteins (Table S3).

\section{Habitat suitability for $Z$. capensis in the LGM}

Multiple models from each algorithm met the TSS $>0.55$ and AUC $>0.8$ criteria and were retained to produce ensembles. Ensemble models obtained the following average validations scores: $\mathrm{TSS}=0.654, \mathrm{AUC}=0.904$, sensitivity $=92.11$, specificity $=73.29$. Predicted distributions of suitable habitat, in terms of SST, differed between present-day and LGM conditions, in terms of geographic location, extent and probability of occurrence (Fig. S2). The highest probability of occurrence can be seen on the south coast (up to $\sim 25^{\circ}$ longitude) and west coast (up to $\sim 18^{\circ}$ latitude) for the present-day projection, and on the western-south coast (up to $\sim 21^{\circ}$ longitude) and west coast (up to $\sim 18^{\circ}$ latitude) for the LGM projection. Ensemble models project an $11.05 \%$ loss and a $10.79 \%$ gain of suitable habitat from the LGM to present-day, with a $26.1 \%$ range shift. These shifts are most evident in the loss of suitable habitat on the south and south-east coasts $\left(\sim 21-27^{\circ}\right.$ 


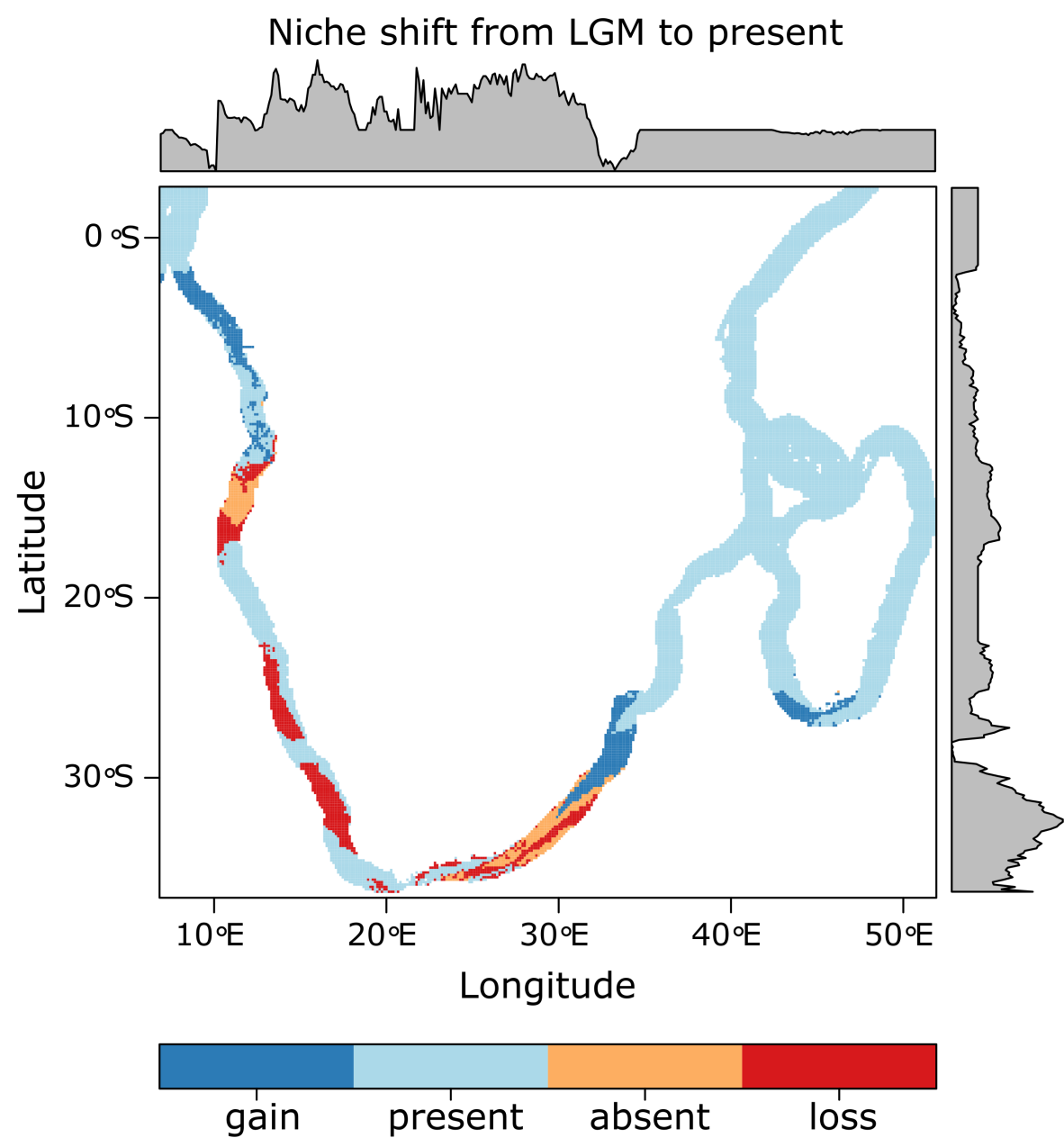

Figure 4 Projected changes in suitable habitat, in terms of SST, from the LGM to present with the probability of occurrence graphically represented along the $x$ and $y$ axes. The western-south coast represents an area where suitable habitat, in terms of temperature, has remained stable from the LGM until the present day.

Full-size DOI: 10.7717/peerj.6806/fig-4

longitude), southern-west coast $\left(\sim 30-35^{\circ}\right.$ latitude), and west coast $\left(\sim 12-18^{\circ}\right.$ latitude $)$, as well as the gain of suitable habitat on the northern-east coast of South Africa $\left(\sim 30-35^{\circ}\right.$ latitude), the south coast of Madagascar and the northern-west coast of Africa $\left(\sim 3-8^{\circ}\right.$ latitude; Fig. 4). Further, within a South African context, the western-south coast represents an area of stable temperature regime, where suitable habitat has occurred from at least as far back as the LGM until the present day (Fig. 4). This can also be seen in patches on the west coast and on the east coast of Africa $\left(\sim 5-25^{\circ}\right.$ latitude).

\section{IBD vs IBE}

Of the 11 environmental variables, seven were selected by the RDA as the most informative (Table 2). The pure RDA of genetic variation against transformed geographic distance was not significant $(P>0.05)$, but was significant when carried out against environmental variation, with $70.4 \%$ of the variation in the data explained by the retained environmental 
variables. Unexpectedly, neither partial RDA analyses, the first conditioned on transformed geographic distance and the other on environmental variation, were significant. Although environmental variation explained such a high percentage of the variation observed in the data, partitioning out the effect of geographic distance on environmental variation rendered the association with genetic variation non-significant.

\section{DISCUSSION}

\section{Genomic diversity of a threatened seagrass}

Genomic variability did not differ greatly between populations with all sites displaying very low heterozygosity and a high inbreeding coefficient $\left(F_{I S}=1\right.$; Table 4$)$. However, sites in cluster one did exhibit slightly higher levels of variability than those in cluster two (Table 4). With such high inbreeding coefficients, it is likely that this species does indeed rely heavily, if not solely, on clonal growth and vegetative reproduction, rather than sexual reproduction (Tables 3 and 4). In terms of reproductive strategy, clonality in seagrasses can vary between species with a continuum from monoclonality to meadows with high clonal diversity (Van Dijk \& Van Tussenbroek, 2010), and the predominance of certain clonal lineages may indicate long-term selection on phenotypes. Such selection may be in response to environmental variables, where conditions are more favourable for clonal lineages, but may also represent shared ancestry prior to historic sea-level fluctuations reshaping the topography of the South African coastline (Ramsay \& Cooper, 2002; Compton, 2011; Ludt \& Rocha, 2015). In the case of Z. capensis, it is likely that a combination of historical (see below) and contemporary factors shape the patterns of observed genomic diversity. Importantly, Z. capensis is unlikely to be influenced by contemporary gene flow between its fragmented and isolated meadows, being restricted to sheltered and low wave action environments (Van Niekerk \& Turpie, 2012). In addition, the lack of recorded sexual reproduction in this species through flowering (McMillan, 1980; D Pillay, pers. comm., 2014 ) is likely to contribute to maintaining clonal populations throughout the range, with important implications for potential restoration efforts in the region.

\section{Shared adaptive divergence across two genomic clusters shaped by historical dynamics}

Although neutral variation can reveal much about a species demographic history, in many cases, patterns revealed from outlier loci can provide unique insights into evolutionary potential and patterns of resilience (Stapley et al., 2010; Guo et al., 2015; Funk et al., 2016; Gaither et al., 2018). Particularly in marine systems where gene flow is generally presumed to be high, signals of outlier loci can help detect population structure (André et al., 2011; Freamo et al., 2011; Hess et al., 2013; Candy et al., 2015; Araneda et al., 2016; Tigano \& Friesen, 2016; Attard et al., 2018). For example, Atlantic herring in the Baltic and North Sea (André et al., 2011), Atlantic salmon in eastern Canada (Freamo et al., 2011), and Chilean blue mussels (Araneda et al., 2016), all exhibit little to no structure in terms of neutral variation but reveal significant population structure for outliers putatively under selection. In $Z$. capensis, despite the generally low levels of genomic variation detected across its range, clustering analyses revealed differentiation of all populations into two major 
clusters when outliers that may represent putatively adaptive variation were considered in addition to neutral data (Fig. 1B). Cluster one comprised of sites from the west and south coast, and cluster two sites from the east coast in addition to one west coast site at Langebaan, Oostewaal, also grouping with this cluster (Fig. 2). In addition, PCoAs support the clustering analyses, with both neutral and adaptive variation (Fig. 2). Interestingly, the PCoAs indicate that east coasts sites are more distantly related than the west and south coast sites. Therefore, east coast sites may have had an earlier origin which supports the likelihood of a refugial area for $Z$. capensis on the east coast.

Temperature-based ensemble models, however, suggest reduced, and more fragmented seagrass habitat along the South African south coast, that is likely to have divided Z. capensis into two clusters with the south-western and east coast possibly representing refugial areas during the LGM, with subsequent dispersal into its present-day distribution. A refugial area on the south-western coast may explain the presence of both clusters in Langebaan Lagoon. Notably, this split between the clusters roughly coincides with the split between described temperate and sub-tropical bioregions (Sink et al., 2012) along which phylogeographic breaks have been recorded for marine coastal species (Von der Heyden, 2009; Teske et al., 2011), including one other saltmarsh plant (Potts, Veldkornet \& Adams, 2016). Given lack of gene flow and apparent high levels of clonality in Z. capensis, the structure detected through outlier loci most likely reflects ancestral adaptation during conditions more conducive to gene flow or incomplete lineage sorting during post-LGM expansion.

Interestingly, although our historical models were based on environmental variables, they broadly mirror the findings of changes in topology and composition of the South African coastline during the last 70,000 years (Toms et al., 2014). During the past 45,000 years, lowered sea level stands of up to $-120 \mathrm{~m}$ caused significant shifts from rocky to sandy/muddy shorelines which isolated populations of obligate rocky shore species. Although $Z$. capensis is found in present-day estuaries, the latter would also have been affected, although the extent of change is unknown. Our findings, in combination with Toms et al. (2014), do however show that combinations of abiotic changes have the potential to influence the population dynamics of marine and estuarine species in the Atlantic/Indian Ocean transition zone, as they have done in Australia over exceedingly short time scales (Puritz et al., 2012).

We provide evidence for a pattern of shared outlier loci for populations across a distinct environmental gradient and large geographic span, despite the presence of two genomic clusters that appear to represent distinct historical lineages. This is in contrast to our hypothesis of distinct population-level signals of adaptive variation as seen in previous studies (Williams \& Oleksiak, 2008; Perrier et al., 2013; Ravinet et al., 2016). All outlier loci were shared among sites with no populations harbouring private outliers (Table S3), suggesting the same genomic basis for each $Z$. capensis meadow with the same suite of genes under selection across sites in response to the various environmental gradients. However, differences in the frequencies of these outlier loci across sites provides the foundation for the two clusters, with sites from cluster one exhibiting outlier loci at lower frequencies compared to cluster two (Fig. 3). Notably, this pattern of differential outlier allele frequencies could be observed even when only considering three outlier loci (Fig. 3). 
The same clustering pattern is detected with both non-simulated and simulated datasets, which were necessary in order for the analysis of pooled data with certain software. This similarity demonstrates that simulated datasets can be used to detect biologically significant evolutionary patterns, regardless of the over-simplifications these simulated datasets may introduce, or the number of SNPs one chooses to employ.

There have been numerous other studies that also report high levels of shared adaptive variation across sites, such as that in Atlantic salmon of eastern Canada, where the allele frequencies of shared outlier loci were used in to assign individuals to their region of origin, assisting with stock management (Freamo et al., 2011). Similarly, in Pacific and Atlantic sticklebacks different allele frequencies of shared outlier loci have been used to distinguish marine and freshwater populations (Jones et al., 2012). At a smaller scale in western Canada, most outlier loci in sticklebacks were specific to single watershed regions (Deagle et al., 2012). Likewise, few shared outlier loci were observed in the periwinkle, Littorina saxatilis, in Sweden (Ravinet et al., 2016), suggesting that the shared or private nature of outlier loci might be highly context specific. Despite the potential for high levels of gene flow and similar selective pressures, $L$. saxatilis populations displayed a considerable amount of unshared genomic divergence, possibly due to complex polygenic traits involved in habitat adaptation.

\section{The contribution of IBD and IBE towards the spatial arrangement of genomic variability in $Z$. capensis}

Despite the low probability of connectivity between sites, due to both the isolated nature of estuaries and the lack of sexual reproduction recorded for this species, geographic distance (IBD) was not a significant driver of the observed genomic variation, with some evidence for IBE in this system. However, because of spatial autocorrelation with environmental variables chosen in this study, there appears to be a large spatial component shaping genomic variation, which cannot be separated from the effect of environmental variables. Our results suggest that IBE plays an important role in shaping genomic variation in this seagrass, in particular dissolved oxygen, annual mean moisture, precipitation and temperature related environmental variables, that were all significantly associated with outlier loci. Although the functional relevance of these outliers is unclear, this may indicate some level of adaptive variation. In addition, it is likely that fine-scale environmental variation, specific to each of the estuaries from which $Z$. capensis were sampled additionally contributes to IBE. However, given the lack of in-situ measurements of important environmental variables for coastal South and eastern Africa, this is not possible to determine at this stage.

\section{CONCLUSIONS}

Zostera capensis along the African coast have not been observed to reproduce sexually, and high clonality combined with low genomic diversity increases their vulnerability to direct human pressures and a changing climate. Genomic similarity between sites however may confer a level of resilience as meadows particularly in the context of restoration (Hughes \& Stachowicz, 2004; McKay et al., 2005; Reynolds, McGlathery \& Waycott, 2012; Baums, 2008). 
Even though there is no significant structure based on neutral loci, the clustering of sites into west and east based on outlier loci may indicate different levels of selection on the same suite of genes, which is not implausible given the environmental and ecological gradients that characterise our study area. Shared outlier loci among independent lineages, coupled with differences in the frequencies of those outlier loci among populations correlated with environmental variability is consistent with the potential for local adaptation. Although we could not directly test for local adaptation, and recognise the need for reciprocal transplant experiments (Kawecki \& Ebert, 2004), the frequency differences among outlier loci may indicate some functional variation, which could in turn influence how different populations respond to changing environmental conditions. Additionally, the two clusters appear in part to be shaped by historical environmental variation, with each cluster linked to climatically stable refugia on the south-western and east coasts. As such, it is important to protect and maintain distinct populations across the distributional range of keystone species in order to safeguard this seagrass and its vital ecosystem services into the future (Hughes \& Stachowicz, 2004). In particular, while Langebaan Lagoon may serve as an ideal focal point for conservation on the west coast, areas on the east coast of South Africa, Mozambique and Kenya should also be targeted for conservation in order to increase resilience and reduce the risk of widespread loss.

\section{ACKNOWLEDGEMENTS}

This study would not have been possible without the assistance of the following individuals in collecting seagrass samples from across southern Africa: Marcel van Zyl, Dr Jaco Barendse, Dr Kyle Smith, Prof. Janine Adams, Rob Nettleton, Dr Leon Vivier and Dr Nina Wambiji.

\section{ADDITIONAL INFORMATION AND DECLARATIONS}

\section{Funding}

This study was supported by the South African National Research Foundation (NRF) through a Scarce Skills Doctoral Scholarship to Nikki Leanne Phair, the Western Indian Ocean Marine Science Association (WIOMSA) through the MARG I grant to Sophie von der Heyden and NSF OA \#1416889 to Robert John Toonen. The funders had no role in study design, data collection and analysis, decision to publish, or preparation of the manuscript.

\section{Grant Disclosures}

The following grant information was disclosed by the authors:

South African National Research Foundation.

Western Indian Ocean Marine Science Association.

MARG I.

NSF OA \#1416889. 


\section{Competing Interests}

Robert Toonen is an Academic Editor for PeerJ.

\section{Author Contributions}

- Nikki Leanne Phair conceived and designed the experiments, performed the experiments, analyzed the data, prepared figures and/or tables, authored or reviewed drafts of the paper, approved the final draft.

- Robert John Toonen contributed reagents/materials/analysis tools, authored or reviewed drafts of the paper, approved the final draft.

- Ingrid Knapp performed the experiments, contributed reagents/materials/analysis tools, authored or reviewed drafts of the paper, approved the final draft, sequencing library preparation.

- Sophie von der Heyden conceived and designed the experiments, contributed reagents/materials/analysis tools, authored or reviewed drafts of the paper, approved the final draft.

\section{Field Study Permissions}

The following information was supplied relating to field study approvals (i.e., approving body and any reference numbers):

The collection of plant material was approved by SanParks and Cape Nature (permit number 0028-AAA008-00159), DAFF and DEA (permit number was RES2014/103).

\section{Data Availability}

The following information was supplied regarding data availability:

The raw data is available at National Center for Biotechnology Information's (NCBI's) Sequence Read Archive (SRA; PRJNA503110) and georeferenced at GeOMe at the project: Zostera capensis pooled RADseq. To access the data go to https://geome-db.org/query and search for "Zostera capensis" in the "any term" search box.

\section{Supplemental Information}

Supplemental information for this article can be found online at http://dx.doi.org/10.7717/ peerj.6806\#supplemental-information.

\section{REFERENCES}

Adams JB, Veldkornet D, Tabot P. 2016. Distribution of macrophyte species and habitats in South African estuaries. South African Journal of Botany 107:5-11 DOI 10.1016/j.sajb.2016.08.001.

Allouche O, Tsoar A, Kadmon R. 2006. Assessing the accuracy of species distribution models: prevalence, kappa and the true skill statistic (TSS). Journal of Applied Ecology 43:1223-1232.

Altschul SF, Madden TL, Schäffer AA, Zhang J, Zhang Z, Miller W, Lipman DJ. 1997. Gapped BLAST and PSI-BLAST: a new generation of protein database search programs. Nucleic Acids Research 25:3389-3402 DOI 10.1093/nar/25.17.3389. 
André C, Larsson LC, Laikre L, Bekkevold D, Brigham J, Carvalho GR, Dahlgren TG, Hutchinson WF, Mariani S, Mudde K, Ruzzante DE. 2011. Detecting population structure in a high gene-flow species, Atlantic herring (Clupea harengus): direct, simultaneous evaluation of neutral vs putatively selected loci. Heredity 106:270-280 DOI 10.1038/hdy.2010.71.

Andrews KR, Good JM, Miller MR, Luikart G, Hohenlohe PA. 2016. Harnessing the power of RADseq for ecological and evolutionary genomics. Nature Reviews Genetics 17:81-92 DOI 10.1038/nrg.2015.28.

Andrews S. 2010. FastQC: a quality control tool for high throughput sequence data. Available at http://www.bioinformatics.babraham.ac.uk/projects/fastqc.

Angeloni F, Wagemaker N, Vergeer P, Ouborg J. 2012. Genomic toolboxes for conservation biologists. Evolutionary Applications 5:130-143

DOI 10.1111/j.1752-4571.2011.00217.x.

Antao T, Lopes A, Lopes RJ, Beja-Pereira A, Luikart G. 2008. LOSITAN: a workbench to detect molecular adaptation based on a Fst-outlier method. BMC Bioinformatics 9:323 DOI 10.1186/1471-2105-9-323.

Araneda C, Larraín MA, Hecht B, Narum S. 2016. Adaptive genetic variation distinguishes Chilean blue mussels (Mytilus chilensis) from different marine environments. Ecology and Evolution 6:3632-3644 DOI 10.1002/ece3.2110.

Arnaud-Haond S, Duarte CM, Diaz-Almela E, Marbà N, Sintes T, Serrão EA. 2012. Implications of extreme life span in clonal organisms: millenary clones in meadows of the threatened seagrass Posidonia oceanica. PLOS ONE 7(2):e30454 DOI 10.1371/journal.pone.0030454.

Arriesgado DM, Kurokochi H, Nakajima Y, Matsuki Y, Uy WH, Fortes MD, Campos WL, Nadaoka K, Lian C. 2016. Population genetic diversity and structure of a dominant tropical seagrass, Cymodocea rotundata, in the Western Pacific region. Marine Ecology 37:786-800 DOI 10.1111/maec.12350.

Attard CRM, Brauer CJ, Sandoval-Castillo J, Faulks LK, Unmack PJ, Gilligan DM, Beheregaray LB. 2018. Ecological disturbance influences adaptive divergence despite high gene flow in golden perch (Macquaria ambigua): implications for management and resilience to climate change. Molecular Ecology 27:196-215 DOI 10.1111/mec.14438.

Barth JMI, Berg PR, Jonsson PR, Bonanomi S, Corell H, Hemmer-Hansen J, Jakobsen KS, Johannesson K, Jorde PE, Knutsen H, Moksnes PO, Star B, Stenseth NC, Svedäng H, Jentoft S, André C. 2017. Genome architecture enables local adaptation of Atlantic cod despite high connectivity. Molecular Ecology 38:42-49.

Baums IB. 2008. A restoration genetics guide for coral reef conservation. Molecular Ecology 17:2796-2811 DOI 10.1111/j.1365-294X.2008.03787.x.

Becheler R, Diekmann O, Hily C, Moalic Y, Arnaud-Haond S. 2010. The concept of population in clonal organisms: mosaics of temporally colonized patches are forming highly diverse meadows of Zostera marina in Brittany. Molecular Ecology 19:2394-2407. 
Bernatchez L. 2016. On the maintenance of genetic variation and adaptation to environmental change: considerations from population genomics in fishes. Journal of Fish Biology 89:2519-2556 DOI 10.1111/jfb.13145.

Bible JM, Sanford E. 2016. Local adaptation in an estuarine foundation species: implications for restoration. Biological Conservation 193:95-102

DOI 10.1016/j.biocon.2015.11.015.

Bonin A, Nicole F, Pompanon F, Miaud C, Taberlet P. 2007. Population adaptive index: a new method to help measure intraspecific genetic diversity and prioritize populations for conservation. Conservation Biology 21:697-708 DOI 10.1111/j.1523-1739.2007.00685.x.

Braconnot P, Otto-Bliesner B, Harrison S, Joussaume S, Peterchmitt JY, Abe-Ouchi A, Crucifix M, Driesschaert E, Fichefet T, Hewitt CD, Kageyama M. 2007. Results of PMIP2 coupled simulations of the Mid-Holocene and Last Glacial Maximum-Part 1: experiments and large-scale features. Climate of the Past 3:261-277.

Braunisch V, Coppes J, Arlettaz R, Suchant R, Schmid H, Bollmann K. 2013. Selecting from correlated climate variables: a major source of uncertainty for predicting species distributions under climate change. Ecography 36:971-983 DOI 10.1111/j.1600-0587.2013.00138.x.

Bricker E, Calladine A, Virnstein R, Waycott M. 2018. Mega clonality in an aquatic plant-a potential survival strategy in a changing environment. Frontiers in Plant Science 9:Article 435 DOI 10.3389/fpls.2018.00435.

Candy JR, Campbell NR, Grinnell MH, Beacham TD, Larson WA, Narum SR. 2015. Population differentiation determined from putative neutral and divergent adaptive genetic markers in Eulachon (Thaleichthys pacificus, Osmeridae), an anadromous Pacific smelt. Molecular Ecology Resources 15:1421-1434 DOI 10.1111/1755-0998.12400.

Carvalho SB, Brito JC, Crespo EJ, Possingham HP. 2011. Incorporating evolutionary processes into conservation planning using species distribution data: a case study with the western Mediterranean herpetofauna. Diversity and Distributions 17:1-14 DOI 10.1111/j.1472-4642.2010.00724.x.

Chefaoui RM, Duarte CM, Serrão EA. 2017. Palaeoclimatic conditions in the Mediterranean explain genetic diversity of Posidonia oceanica seagrass meadows. Scientific Reports 7:2732.

Chen H, Boutros PC. 2011. VennDiagram: a package for the generation of highlycustomizable Venn and Euler diagrams in R. BMC Bioinformatics 12:35 DOI 10.1186/1471-2105-12-35.

Compton JS. 2011. Pleistocene sea-level fluctuations and human evolution on the southern coastal plain of South Africa. Quaternary Science Reviews 30:506-527 DOI 10.1016/j.quascirev.2010.12.012.

Conesa A, Gotz S, Garcia-Gomez JM, Terol J, Talon M, Robles M. 2005. Blast2GO: a universal tool for annotation, visualization and analysis in functional genomics research. Bioinformatics 21:3674-3676 DOI 10.1093/bioinformatics/bti610. 
Corander J, Marttinen P. 2006. Bayesian identification of admixture events using multilocus molecular markers. Molecular Ecology 15:2833-2843 DOI 10.1111/j.1365-294X.2006.02994.x.

Corander J, Marttinen P, Mäntyniemi S. 2006. A Bayesian method for identification of stock mixtures from molecular marker data. Fishery Bulletin 104:550-558.

Cure K, Thomas L, Hobbs JPA, Fairclough DV, Kennington WJ. 2017. Genomic signatures of local adaptation reveal source-sink dynamics in a high gene flow fish species. Scientific Reports 7:1-10 DOI 10.1038/s41598-016-0028-x.

Da Fonseca R, Albrechtsen A, Sibbesen JA, Maretty L, Zepeda-mendoza ML, Campos PF, Pereira RJ. 2016. Next-generation biology: sequencing and data analysis approaches for non-model organisms. Marine Genomics 30:3-13 DOI 10.1016/j.margen.2016.04.012.

Dalongeville A, Benestan L, Mouillot D, Lobreaux S, Manel S. 2018. Combining six genome scan methods to detect candidate genes to salinity in the Mediterranean striped red mullet (Mullus surmuletus). BMC Genomics 19:1-13 DOI 10.1186/s12864-017-4368-0.

De Villemereuil P, Gaggiotti OE. 2015. A new F ST -based method to uncover local adaptation using environmental variables. Methods in Ecology and Evolution 6:1248-1258 DOI 10.1111/2041-210X.12418.

Deagle BE, Jones FC, Chan YF, Absher DM, Kingsley DM, Reimchen TE. 2012. Population genomics of parallel phenotypic evolution in stickleback across streamlake ecological transitions. Proceedings of the Royal Society B: Biological Sciences 279:1277-1286 DOI 10.1098/rspb.2011.1552.

Dennenmoser S, Vamosi SM, Nolte AW, Rogers SM. 2016. Adaptive genomic divergence under high gene flow between freshwater and brackish-water ecotypes of prickly sculpin (Cottus asper) revealed by Pool-Seq. Molecular Ecology 26:25-42.

Diekmann OE, Coyer JA, Ferreira J, Olsen JL, Stam WT, Pearson GA, Serrão EA. 2005. Population genetics of Zostera noltii along the west Iberian coast: consequences of small population size, habitat discontinuity and near-shore currents. Marine Ecology Progress Series 290:89-96 DOI 10.3354/meps290089.

Ellegren H. 2014. Genome sequencing and population genomics in non-model organisms. Trends in Ecology \& Evolution 29:51-63 DOI 10.1016/j.tree.2013.09.008.

Evans SM, Sinclair EA, Poore AG, Steinberg P, Kendrick GA, Verge A. 2014. Genetic diversity in threatened Posidonia australis seagrass meadows. Conservation Genetics 15:717-728.

Fielding AH, Bell JF. 1997. A review of methods for the assessment of prediction errors in conservation presence/absence models. Environmental Conservation 24:38-49.

Foll M, Gaggiotti OE. 2008. A genome-scan method to identify selected loci appropriate for both dominant and codominant markers: a Bayesian perspective. Genetics 180:977-993 DOI 10.1534/genetics.108.092221. 
Freamo H, O'reilly P, Berg PR, Lien S, Boulding EG. 2011. Outlier SNPs show more genetic structure between two Bay of Fundy metapopulations of Atlantic salmon than do neutral SNPs. Molecular Ecology Resources 11:254-267 DOI 10.1111/j.1755-0998.2010.02952.x.

Funk WC, Lovich RE, Hohenlohe PA, Hofman CA, Morrison SA, Sillett TS, Ghalambor CK, Maldonado JE, Rick TC, Day MD, Polato NR. 2016. Adaptive divergence despite strong genetic drift: genomic analysis of the evolutionary mechanisms causing genetic differentiation in the island fox (Urocyon littoralis). Molecular Ecology 25:2176-2194 DOI 10.1111/mec.13605.

Funk WC, McKay JK, Hohenlohe PA, Allendorf FW. 2012. Harnessing genomics for delineating conservation units. Trends in Ecology \& Evolution 27:489-496 DOI 10.1016/j.tree.2012.05.012.

Futschik A, Schlötterer C. 2010. The next generation of molecular markers from massively parallel sequencing of pooled DNA samples. Genetics 186:207-218 DOI 10.1534/genetics.110.114397.

Garcia HE, Locarnini RA, Boyer TP, Antonov JI, Baranova OK, Zweng MM, Reagan JR, Johnson DR. 2013. World Ocean Atlas 2013, Volume 3: dissolved oxygen, apparent oxygen utilization, and oxygen saturation. In: Levitus S, Mishonov A, eds. NOAA Atlas NESDIS 75.

Gaither MR, Bernal MA, Coleman RR, Bowen BW, Jones SA, Simison WB, Rocha LA. 2015. Genomic signatures of geographic isolation and natural selection in coral reef fishes. Molecular Ecology 24:1543-1557 DOI 10.1111/mec.13129.

Gaither MR, Gkafas GA, De Jong M, Sarigol F, Neat F, Regnier T, Moore D, Gröcke DR, Hall N, Liu X, Kenny J. 2018. Genomics of habitat choice and adaptive evolution in a deep-sea fish. Nature Ecology and Evolution 2:1-8 DOI 10.1038/s41559-017-0440-z.

Green EP, Short FT. 2003. World Atlas of Seagrasses. Berkeley: University of California Press.

Greve T, Binzer T. 2004. Which factors regulate seagrass growth and distribution? In: Borum J, Duatre CM, Krause-Jensen D, Greve TM, eds. European seagrassesan introduction to monitoring and management. Hilleroed: The M\&MS project publication, 19-23.

Guisan A, Thuiller W. 2005. Predicting species distribution: offering more than simple habitat models. Ecology Letters 8:993-1009 DOI 10.1111/j.1461-0248.2005.00792.x.

Guo B, DeFaveri J, Sotelo G, Nair A, Merilä J. 2015. Population genomic evidence for adaptive differentiation in Baltic Sea three-spined sticklebacks. BMC Biology 13:19 DOI 10.1186/s12915-015-0130-8.

Guo B, Li Z, Merila J. 2016. Population genomic evidence for adaptive differentiation in the Baltic Sea herring. Molecular Ecology 25:2833-2852 DOI 10.1111/mec.13657.

Hall L, Hanisak M, Virnstein R. 2006. Fragments of the seagrasses Halodule wrightii and Halophila johnsonii as potential recruits in Indian River Lagoon, Florida. Marine Ecology Progress Series 310:109-117 DOI 10.3354/meps310109.

Hanson JO, Rhodes JR, Riginos C, Fuller RA. 2017. Environmental and geographic variables are effective surrogates for genetic variation in conservation planning. 
Proceedings of the National Academy of Sciences of the United States of America 114:12755-12760.

Harrell Jr FE, Dupont MC. 2006. The Hmisc Package. R package version 3.4-2.

Harris LN, Taylor EB. 2010. Pleistocene glaciations and contemporary genetic diversity in a Beringian fish, the broad whitefish, Coregonus nasus (Pallas): inferences from microsatellite DNA variation. Journal of Evolutionary Biology 23:72-86 DOI 10.1111/j.1420-9101.2009.01858.x.

Hernawan UE, Van Dijk K, Kendrick GA, Feng M, Biffin E, Lavery PS, McMahon K. 2017. Historical processes and contemporary ocean currents drive genetic structure in the seagrass Thalassia hemprichii in the Indo-Australian Archipelago. Molecular Ecology 26(4):1008-1021 DOI 10.1111/mec.13966.

Hess JE, Campbell NR, Close DA, Docker MF, Narum SR. 2013. Population genomics of Pacific lamprey: adaptive variation in a highly dispersive species. Molecular Ecology 22(11):2898-2916 DOI 10.1111/mec.12150.

Hewitt G. 2000. The genetic legacy of the Quaternary ice ages. Nature 405:907-913 DOI 10.1038/35016000.

Hoban S, Kelley JL, Lotterhos KE, Antolin MF, Bradburd G, Lowry DB, Poss ML, Reed LK, Storfer A, Whitlock MC. 2016. Finding the genomic basis of local adaptation: pitfalls, practical solutions, and future directions. The American Naturalist 188:379-397 DOI 10.1086/688018.

Hohenlohe PA, Bassham S, Etter PD, Stiffler N, Johnson EA, Cresko WA. 2010. Population genomics of parallel adaptation in threespine stickleback using sequenced RAD tags. PLOS Genetics 6:e1000862 DOI 10.1371/journal.pgen.1000862.

Huang CL, Ho CW, Chiang YC, Shigemoto Y, Hsu TW, Hwang CC, Ge XJ, Chen C, Wu TH, Chou CH, Huang HJ. 2014. Adaptive divergence with gene flow in incipient speciation of Miscanthus floridulus/sinensis complex (Poaceae). Plant Journal 80:834-847 DOI 10.1111/tpj.12676.

Hughes AR, Stachowicz JJ. 2004. Genetic diversity enhances the resistance of a seagrass ecosystem to disturbance. Proceedings of the National Academy of Sciences of the United States of America 101:8998-9002 DOI 10.1073/pnas.0402642101.

Jones FC, Chan YF, Schmutz J, Grimwood J, Brady SD, Southwick AM, Absher DM, Myers RM, Reimchen TE, Deagle BE, Schluter D. 2012. A genome-wide SNP genotyping array reveals patterns of global and repeated species-pair divergence in sticklebacks. Current Biology 22:83-90 DOI 10.1016/j.cub.2011.11.045.

Jones P, Binns D, Chang HY, Fraser M, Li W, McAnulla C, McWilliam H, Maslen J, Mitchell A, Nuka G, Pesseat S. 2014. InterProScan 5: genome-scale protein function classification. Bioinformatics 30:1236-1240 DOI 10.1093/bioinformatics/btu031.

Jover MA, Del Castillo-Agudo L, Garcia-Carrascosa M, Segura J. 2003. Random amplified polymorphic DNA assessment of diversity in western Mediterranean populations of the seagrass Posidonia oceanica. American Journal of Botany 90:364-369 DOI 10.3732/ajb.90.3.364.

Kawecki TJ, Ebert D. 2004. Conceptual issues in local adaptation. Ecology Letters 7:1225-1241 DOI 10.1111/j.1461-0248.2004.00684.x. 
Keenan K, Mcginnity P, Cross TF, Crozier WW, Prodhl PA. 2013. DiveRsity: an $\mathrm{R}$ package for the estimation and exploration of population genetics parameters and their associated errors. Methods in Ecology and Evolution 4:782-788 DOI 10.1111/2041-210X.12067.

Kelly DW, MacIsaac HJ, Heath DD. 2006. Vicariance and dispersal effects on phylogeographic structure and speciation in a widespread estuarine invertebrate. Evolution 60:257-267 DOI 10.1111/j.0014-3820.2006.tb01104.x.

Kendrick GA, Orth RJ, Statton J, Hovey R, Ruiz Montoya L, Lowe RJ, Krauss SL, Sinclair EA. 2016. Demographic and genetic connectivity: the role and consequences of reproduction, dispersal and recruitment in seagrasses. Biological Reviews 92:921-938.

Knapp I, Puritz J, Bird C, Whitney J, Sudek M, Forsman Z, Toonen R. 2016. ezRADan accessible next-generation RAD sequencing protocol suitable for non-model organisms_v3. 1 Protocols. io Life Sciences Protocol Repository. Available at https:// www.protocols.io/view/ezrad-an-accessible-next-generation-rad-sequencing-e9pbh5n.

Kofler R, Betancourt AJ, Schlötterer C. 2012. Sequencing of pooled DNA samples (PoolSeq) uncovers complex dynamics of transposable element insertions in Drosophila melanogaster. PLOS Genetics 8:e1002487 DOI 10.1371/journal.pgen.1002487.

Kofler R, Orozco-terWengel P, Maio N De, Pandey R. 2011. PoPoolation: a toolbox for population genetic analysis of next generation sequencing data from pooled individuals. PLOS ONE 6:1-9.

Kofler R, Pandey RV, Schlötterer C. 2011. PoPoolation2: identifying differentiation between populations using sequencing of pooled DNA samples (Pool-Seq). Bioinformatics 27:3435-3436 DOI 10.1093/bioinformatics/btr589.

Kriticos DJ, Webber BL, Leriche A, Ota N, Macadam I, Bathols J, Scott JK. 2012. CliMond: global high-resolution historical and future scenario climate surfaces for bioclimatic modelling. Methods in Ecology and Evolution 3:53-64 DOI 10.1111/j.2041-210X.2011.00134.x.

Lee H, Golicz AA, Bayer PE, Jiao Y, Tang H, Paterson AH, Sablok G, Krishnaraj RR, Chan CK, Batley J, Kendrick GA. 2016. The Genome of a Southern Hemisphere Seagrass Species (Zostera muelleri). Plant Physiology 172:272-283 DOI 10.1104/pp.16.00868.

Legendre P, Legendre LF. 2012. Numerical ecology. 3rd edition. Amsterdam: Elsevier. Legendre P, Oksanen J, Ter Braak CJ. 2011. Testing the significance of canonical axes in redundancy analysis. Methods in Ecology and Evolution 2:269-277 DOI 10.1111/j.2041-210X.2010.00078.x.

Leprieur F, Colosio S, Descombes P, Parravicini V, Kulbicki M, Cowman PF, Bellwood DR, Mouillot D, Pellissier L. 2016. Historical and contemporary determinants of global phylogenetic structure in tropical reef fish faunas. Ecography 39:825-835.

Lexer C, Wüest R, Mangili S. 2014. Genomics of the divergence continuum in an African plant biodiversity hotspot, I: drivers of population divergence in Restio capensis (Restionaceae). Molecular Ecology 23:4373-4386 DOI 10.1111/mec.12870.

Li H. 2013. Aligning sequence reads, clone sequences and assembly contigs with BWAMEM. ArXiv preprint. arXiv:1303.3997v2. 
Li H, Handsaker B, Wysoker A, Fennell T, Ruan J, Homer N, Marth G, Abecasis G, Durbin R. 2009. The sequence alignment/map format and SAMtools. Bioinformatics Application Note 25:2078-2079 DOI 10.1093/bioinformatics/btp352.

Limborg MT, Pedersen JS, Hemmer-Hansen J, Tomkiewicz J, Bekkevold D. 2009. Genetic population structure of European sprat Sprattus sprattus: differentiation across a steep environmental gradient in a small pelagic fish. Marine Ecology Progress Series 379:213-224 DOI 10.3354/meps07889.

Lischer HEL, Excoffier L. 2012. PGDSpider: an automated data conversion tool for connecting population genetics and genomics programs. Bioinformatics 28:298-299 DOI 10.1093/bioinformatics/btr642.

Locarnini RA, Mishonov AV, Antonov JI, Boyer TP, Garcia HE, Baranova OK, Zweng MM, Paver CR, Reagan JR, Johnson DR, Hamilton M, Seidov D. 2013. World Ocean Atlas 2013, Volume 1: Temperature. In: Levitus S, Mishonov E, eds. NOAA Atlas NESDIS 73.

Lowry DB, Hoban S, Kelley JL, Lotterhos KE, Reed LK, Antolin MF, Storfer A. 2017. Breaking RAD: an evaluation of the utility of restriction site-associated DNA sequencing for genome scans of adaptation. Molecular Ecology Resources 17:142-152 DOI 10.1111/1755-0998.12635.

Lucek K, Keller I, Nolte AW, Seehausen O. 2018. Distinct colonization waves underlie the diversification of the freshwater sculpin (Cottus gobio) in the Central European Alpine region. Journal of Evolutionary Biology 31:1254-1267.

Ludt WB, Rocha LA. 2015. Shifting seas: the impacts of Pleistocene sea-level fluctuations on the evolution of tropical marine taxa. Journal of Biogeography 42:25-38 DOI 10.1111/jbi.12416.

Luu K, Bazin E, Blum MGB. 2016. pcadapt: an R package to perform genome scans for selection based on principal component analysis. bioRxiv 056135 .

Manthey JD, Moyle RG. 2015. Isolation by environment in white-breasted nuthatches (Sitta carolinensis) of the Madrean Archipelago sky islands: a landscape genomics approach. Molecular Ecology 24:3628-3638 DOI 10.1111/mec.13258.

Marques DA. 2017. Adaptation despite gene flow? Low recombination helps. Molecular Ecology 26:4361-4363 DOI 10.1111/mec.14251.

McKay JK, Christian CE, Harrison S, Rice KJ. 2005. How local is local?-a review of practical and conceptual issues in the genetics of restoration. Restoration Ecology 13:432-440 DOI 10.1111/j.1526-100X.2005.00058.x.

Mckinney G, Larson W, Seed L, Seeb JE. 2016. RADseq provides unprecedented insights into molecular ecology and evolutionary genetics: comment on Breaking RAD by Lowry et al. (2016). Molecular Ecology Resources 17:356-361.

McMillan C. 1980. Flowering under controlled conditions by Cymodocea serrulata, Halophila stipulacea, Syringodium isoetifolium, Zostera capensis and Thalassia hemprichii from Kenya. Aquatic Botany 8:323-336

DOI 10.1016/0304-3770(80)90062-5.

Mead A, Griffiths CL, Branch GM, McQuaid CD, Blamey LK, Bolton JJ, Anderson RJ, Dufois F, Rouault M, Froneman PW, Whitfield AK. 2013. Human-mediated drivers 
of change-impacts on coastal ecosystems and marine biota of South Africa. African Journal of Marine Science 35:403-425.

Mendez M, Rosenbaum HC, Subramaniam A, Yackulic C, Bordino P. 2010. Isolation by environmental distance in mobile marine species: molecular ecology of franciscana dolphins at their southern range. Molecular Ecology 19:2212-2228 DOI 10.1111/j.1365-294X.2010.04647.x.

Moura AE, Kenny JG, Chaudhuri R, Hughes MA, Welch JA, Reisinger RR, De Bruyn PJN, Dahlheim ME, Hall N, Hoelzel AR. 2014. Population genomics of the killer whale indicates ecotype evolution in sympatry involving both selection and drift. Molecular Ecology 23:5179-5192 DOI 10.1111/mec.12929.

Muñiz Salazar R, Talbot SL, Sage GK, Ward DH, Cabello-Pasini A. 2005. Population genetic structure of annual and perennial populations of Zostera marina L., along the Pacific coast of Baja California and the Gulf of California. Molecular Ecology 14:711-722 DOI 10.1111/j.1365-294X.2005.02454.x.

Nakajima Y, Matsuki Y, Lian C, Fortes MD, Uy WH, Campos WL, Nakaoka M, Nadaoka K. 2014. The Kuroshio Current influences genetic diversity and population genetic structure of a tropical seagrass, Enhalus acoroides. Molecular Ecology 23:6029-6044 DOI 10.1111/mec.12996.

Narum SR, Hess JE. 2011. Comparison of FST outlier tests for SNP loci under selection. Molecular Ecology Resources 11:184-194 DOI 10.1111/j.1755-0998.2011.02987.x.

Nielsen ES, Henriques R, Toonen RJ, Knapp ISS, Guo B, Von der Heyden S. 2018. Complex signatures of genomic variation of two non-model marine species in a homogeneous environment. BMC Genomics 19:1-16 DOI 10.1186/s12864-017-4368-0.

Oksanen J, Blanchet FG, Kindt R, Legendre P, Minchin PR, O’Hara RB, Simpson GL, Solymos $\mathrm{P}$, Stevens MH, Wagner H. 2015. vegan: community ecology package. $\mathrm{R}$ package version 2.3-0. Available at https://github.com/vegandevs/vegan.

O'Leary SJ, Puritz JB, Willis SC, Hollenbeck CM, Portnoy DS. 2018. These aren't the loci you're looking for: principles of effective SNP filtering for molecular ecologists. Molecular Ecology 27:3193-3206 DOI 10.1111/mec.14792.

Olsen JL, Rouzé P, Verhelst B, Lin YC, Bayer T, Collen J, Dattolo E, De Paoli E, Dittami S, Maumus F, Michel G. 2016. The genome of the seagrass Zostera marina reveals angiosperm adaptation to the sea. Nature 530:1-17.

Olsen JL, Stam WT, Coyer JA, Reusch TB, Billingham M, Boström C, Calvert E, Christie H, Granger S, Lumiere RL, Milchakova N. 2004. North Atlantic phylogeography and large scale population differentiation of the seagrass Zostera marina L. Molecular Ecology 13:1923-1941 DOI 10.1111/j.1365-294X.2004.02205.x.

Orth RJ, Carruthers TJ, Dennison WC, Duarte CM, Fourqurean JW, Heck KL, Hughes AR, Kendrick GA, Kenworthy WJ, Olyarnik S, Short FT. 2006. A global crisis for seagrass ecosystems. Bioscience 56:987-996

DOI 10.1641/0006-3568(2006)56[987:AGCFSE]2.0.CO;2.

Perrier C, Bourret V, Kent MP, Bernatchez L. 2013. Parallel and nonparallel genomewide divergence among replicate population pairs of freshwater and anadromous Atlantic salmon. Molecular Ecology 22:5577-5593 DOI 10.1111/mec.12500. 
Phan TTH, De Raeymaeker M, Luong QD, Triest L. 2017. Clonal and genetic diversity of the threatened seagrass Halophila beccarii in a tropical lagoon: resilience through short distance dispersal. Aquatic Botany 142:96-104

DOI 10.1016/j.aquabot.2017.07.006.

Potts AJ, Veldkornet DA, Adams JB. 2016. A phylogeographic break in a South African coastal saltmarsh macrophyte, Juncus kraussii. South African Journal of Botany 107:80-83 DOI 10.7196/SAMJ.2017.v107i1.10907.

Procaccini G, Olsen JL, Reusch TB. 2007. Contribution of genetics and genomics to seagrass biology and conservation. Journal of Experimental Marine Biology and Ecology 350:234-259 DOI 10.1016/j.jembe.2007.05.035.

Prunier R, Akman M, Kremer CT, Aitken N, Chuah A, Borevitz J, Holsinger KE. 2017. Isolation by distance and isolation by environment contribute to population differentiation in Protea repens (Proteaceae L.), a widespread South African species. American Journal of Botany 104:674-684 DOI 10.3732/ajb.1600232.

Puritz JB, Keever CC, Addison JA, Byrne M, Hart MW, Grosberg RK, Toonen RJ. 2012. Extraordinarily rapid life-history divergence between Cryptasterina sea star species. Proceedings of the Royal Society of London B: Biological Sciences 279:3914-3922 DOI 10.1098/rspb.2012.1343.

Putra ING, Syamsuni YF, Subhan B, Pharmawati M, Madduppa H. 2018. Strong genetic differentiation in tropical seagrass Enhalus acoroides (Hydrocharitaceae) at the Indo-Malay Archipelago revealed by microsatellite DNA. PeerJ 6:e4315 DOI 10.7717/peerj.4315.

QGIS Development Team. 2012. QGIS Geographic Information System. Open Source Geospatial Foundation Project.

R Core Development Team. 2008. R: a language and environment for statistical computing. Vienna: R Foundation for Statistical Computing. Available at http://www.Rproject.org.

Ramsay PJ, Cooper J. 2002. Late quaternary sea-level change in South Africa. Quaternary Research 57:82-90 DOI 10.1006/qres.2001.2290.

Ravinet M, Westram A, Johannesson K, Butlin RK, André C, Panova M. 2016. Shared and nonshared genomic divergence in parallel ecotypes of Littorina saxatilis at a local scale. Molecular Ecology 25:287-305 DOI 10.1111/mec.13332.

Reynolds LK, McGlathery KJ, Waycott M. 2012. Genetic diversity enhances restoration success by augmenting ecosystem services. PLOS ONE 7:e38397 DOI 10.1371/journal.pone.0038397.

Roberts DW. 2007. labdsv: ordination and multivariate analysis for ecology. R package version 1.1. Available at http:// ecology.msu.montana.edu/labdsv/R.

Rodríguez-Zárate CJ, Sandoval-Castillo J, Van Sebille E, Keane RG, RochaOlivares A, Urteaga J, Beheregaray LB. 2018. Isolation by environment in the highly mobile olive ridley turtle (Lepidochelys olivacea) in the eastern Pacific. Proceedings of the Royal Society B: Biological Sciences 285:Article 20180264 DOI 10.1098/rspb.2018.0264. 
Ruggiero MV, Turk R, Procaccini G. 2002. Genetic identity and homozygosity in North- Adriatic populations of Posidonia oceanica: an ancient, post-glacial clone? Conservation Genetics 3:71-74.

Savolainen O, Lascoux M, Merilä J. 2013. Ecological genomics of local adaptation. Nature Reviews Genetics 14:807-820 DOI 10.1038/nrg3522.

Sbrocco EJ. 2014. Paleo-MARSPEC: Gridded ocean climate layers for the mid-Holocene and Last Glacial Maximum. Ecology 95:1710.

Sbrocco EJ, Barber PH. 2013. MARSPEC: ocean climate layers for marine spatial ecology. Ecology 94:979.

Schlötterer C, Tobler R, Kofler R, Nolte V. 2014. Sequencing pools of individualsmining genome-wide polymorphism data without big funding. Nature Reviews Genetics 15:749-763.

Sexton JP, Hangartner SB, Hoffmann AA. 2014. Genetic isolation by environment or distance: which pattern of gene flow is most common? Evolution 68:1-15 DOI 10.1111/evo.12258.

Sham P, Bader JS, Craig I, O'Donovan M, Owen M. 2002. DNA pooling: a tool for largescale association studies. Nature Reviews Genetics 3:862-871.

Sherman CDH, York PH, Smith TM, Macreadie PI. 2016. Fine-scale patterns of genetic variation in a widespread clonal seagrass species. Marine Biology 163:1-11 DOI 10.1007/s00227-015-2782-X.

Short FT, Coles R, Waycott M, Bujang JS, Fortes M, Prathep A, Kamal AHM, Jagtap TG, Bandeira S, Freeman A, Erftemeijer P, La Nafie YA, Vergara S, Calumpong HP, Makm I. 2010. Zostera capensis. In: IUCN 2013. IUCN Red List of Threatened Species. Version 2013.2. Available at http://www.iucnredlist.org (accessed on 27 March 2014).

Sinclair E, Krauss S, Anthony J, Hovey R, Kendrick G. 2014. The interaction of environment and genetic diversity within meadows of the seagrass Posidonia australis (Posidoniaceae). Marine Ecology Progress Series 506:87-98 DOI 10.3354/meps10812.

Stapley J, Reger J, Feulner PGD, Smadja C, Galindo J, Ekblom R, Bennison C, Ball AD, Beckerman AP, Slate J. 2010. Adaptation genomics: the next generation. Trends in Ecology and Evolution 25:705-712 DOI 10.1016/j.tree.2010.09.002.

Teske PR, Von der Heyden S, McQuaid CD, Barker NP. 2011. A review of marine phylogeography in southern Africa. South African Journal of Science 107:43-53 DOI 10.3354/meps314283.

Thuiller W, Georges D, Engler R, Breiner F, Georges MD, Thuiller CW. 2016. Package 'biomod2'. Species distribution modeling within an ensemble forecasting framework. Available at https://CRAN.R-project.org/package=biomod2.

Tigano A, Friesen VL. 2016. Genomics of local adaptation with gene flow. Molecular Ecology 25:2144-2164 DOI 10.1111/mec.13606.

Toms JA, Compton JS, Smale M, Von der Heyden S. 2014. Variation in palaeoshorelines explains contemporary population genetic patterns of rocky shore species. Biology Letters 10:Article 20140330 DOI 10.1098/rsbl.2014.0330. 
Toonen RJ, Puritz JB, Forsman ZH, Whitney JL, Fernandez-Silva I, Andrews KR, Bird CE. 2013. ezRAD: a simplified method for genomic genotyping in non-model organisms. PeerJ 1:e203 DOI 10.7717/peerj.203.

Valle M, Chust G, Del Campo A, Wisz MS, Olsen SM, Garmendia JM, Borja Á. 2014. Projecting future distribution of the seagrass Zostera noltii under global warming and sea level rise. Biological Conservation 170:74-85.

Van Dijk J, Van Tussenbroek B. 2010. Clonal diversity and structure related to habitat of the marine angiosperm Thalassia testudinum along the Atlantic coast of Mexico. Aquatic Botany 92:63-69 DOI 10.1016/j.aquabot.2009.10.005.

Van Dijk J, Van Tussenbroek B, Jiménez-Durán K, Márquez-Guzmán G, Ouborg J. 2009. High levels of gene flow and low population genetic structure related to high dispersal potential of a tropical marine angiosperm. Marine Ecology Progress Series 390:67-77 DOI 10.3354/meps08190.

Van Niekerk L, Turpie J (eds.) 2012. National biodiversity assessment 2011 volume 3: estuary component technical report. Available at http:// mpaforum.org.za/wpcontent/uploads/2016/08/Nat-Biodiversity-AssTechRepEstuary.pdf.

Varela S, Lima-Ribeiro MS, Terribile LC. 2015. A short guide to the climatic variables of the last glacial maximum for biogeographers. PLOS ONE 10(6):e0129037 DOI 10.1371/journal.pone.0129037.

Von der Heyden S. 2009. Why do we need to integrate population genetics into South African marine protected area planning? African Journal of Marine Science 31:263-269.

Von der Heyden S. 2017. Making evolutionary history count: biodiversity planning for coral reef fishes and the conservation of evolutionary processes. Coral Reefs 36:183-194.

Wang IJ, Bradburd GS. 2014. Isolation by environment. Molecular Ecology 23:5649-5662 DOI 10.1111/mec.12938.

Waycott M, Duarte CM, Carruthers TJ, Orth RJ, Dennison WC, Olyarnik S, Calladine A, Fourqurean JW, Heck KL, Hughes AR, Kendrick GA. 2009. Accelerating loss of seagrasses across the globe threatens coastal ecosystems. Proceedings of the National Academy of Sciences United States of America 106:12377-12381 DOI 10.1073/pnas.0905620106.

Weatherall EJ, Jackson EL, Hendry RA, Campbell ML. 2016. Quantifying the dispersal potential of seagrass vegetative fragments: a comparison of multiple subtropical species. Estuarine, Coastal and Shelf Science 169:207-215 DOI 10.1016/j.ecss.2015.11.026.

Weber JN, Bradburd GS, Stuart YE, Stutz WE, Bolnick DI. 2017. Partitioning the effects of isolation by distance, environment, and physical barriers on genomic divergence between parapatric threespine stickleback. Evolution 71:342-356 DOI 10.1111/evo.13110.

Whittaker KA, Rynearson TA. 2017. Evidence for environmental and ecological selection in a microbe with no geographic limits to gene flow. Proceedings of the National Academy of Sciences of the United States of America 16:2651-2656. 
Wickham H. 2009. ggplot2: elegant graphics for data analysis. New York: SpringerVerlag.

Williams LM, Oleksiak MF. 2008. Signatures of selection in natural populations adapted to chronic pollution. BMC Evolutionary Biology 8:282 DOI 10.1186/1471-2148-8-282.

Williams SL. 2017. Reduced genetic diversity in eelgrass transplantations affects both population growth and individual fitness. Ecological Applications 11:1472-1488.

Wright D, Bishop JM, Matthee CA, Von der Heyden S. 2015. Genetic isolation by distance reveals restricted dispersal across a range of life histories: implications for biodiversity conservation planning across highly variable marine environments. Diversity and Distributions 21:698-710 DOI 10.1111/ddi.12302.

Yeaman S. 2013. Genomic rearrangements and the evolution of clusters of locally adaptive loci. Proceedings of the National Academy of Sciences of the United States of America 110:E1743-E1751.

Zweng MM, Reagan JR, Antonov JI, Locarnini RA, Mishonov AV, Boyer TP, Garcia HE, Baranova OK, Johnson DR, Seidov D, Biddle MM. 2013. World ocean atlas 2013. Volume 2, Salinity. NOAA Atlas NESDIS 74. Available at https:// repository.library. noaa.gov/view/noaa/ 14848. 